\title{
Throughput and product quality control for a grinding mill circuit using Non-linear MPC is
}

\author{
J.D. le Roux ${ }^{\mathrm{a}, *}$, L.E. Olivier ${ }^{\mathrm{a}}$, M. A. Naidoo ${ }^{\mathrm{a}}$, R. Padhi ${ }^{\mathrm{b}, 1}$, I. K. Craig ${ }^{\mathrm{a}}$ \\ ${ }^{a}$ Department of Electrical, Electronic and Computer Engineering, University of Pretoria, Pretoria, South Africa. \\ ${ }^{b}$ Department of Aerospace Engineering, Indian Institute of Science, Bangalore, India.
}

\begin{abstract}
A non-linear model-based control architecture for a single-stage grinding mill circuit closed with a hydrocyclone is proposed. The control architecture aims to achieve independent control of circuit throughput and product quality, and consists of a non-linear model predictive controller for grinding mill circuit control, and a dynamic inversion controller to control the fast sump dynamics. A particle filter is used to estimate the mill states, and an algebraic routine is used to estimate the sump states. The observers make use of real-time continuous measurements commonly available on industrial plants. Simulation results show that control objectives can be achieved by the controller despite the presence of measurement noise and disturbances.
\end{abstract}

Keywords: dynamic inversion, grinding mill, model predictive control, non-linear, particle filter, run-of-mine, state estimation

\section{Introduction}

A run-of-mine (ROM) ore milling circuit is primarily used to grind mined ore containing valuable metals into a very fine product. The fine material is sent to a downstream process after grinding to separate the valuable metal from the gangue material. The separation process results in a concentrate of valuable metals, and a tailings stream of waste. As shown by McIvor and Finch (1991) and Munoz and Cipriano (1999), a sufficiently fine milling circuit product results in improved recovery of valuable metals in the separator concentrate. However, the finer product of the comminution circuit comes at the cost of reduced throughput. Although it is desirable to have independent control of the circuit's product quality and throughput, these variables are inversely proportional (Bauer and Craig, 2008). A degree of independent control of quality and throughput cannot realistically be achieved without sufficient independent manipulated variables.

\subsection{Control of grinding mill circuits}

Whether to achieve a consistent product quality or throughput, a ROM ore milling circuit is a difficult process to control because of non-linearities, large time delays, unmeasured disturbances, process variables that are difficult to measure, and modelling uncertainties (Coetzee et al., 2010; Hodouin, 2011). Traditionally milling circuits are controlled by decentralized proportional-integral-derivative (PID) controllers (Wei and Craig, 2009b) despite the multivariable nature of the circuits (Pomerleau et al., 2000). Significant improvement in product quality, throughput and power consumption is possible through multivariable control techniques. This is illustrated by the industrial implementation of a multivariable controller on a ROM ore grinding circuit documented in Hulbert et al. (1990) and Craig et al. (1992b), the robust controller applied

\footnotetext{
${ }^{2}$ A subset of this work was presented at the 19th IFAC World Conference (Cape Town, 2014) (Naidoo et al., 2014).

${ }^{*}$ Corresponding author. Address: Department of Electrical, Electronic, and Computer Engineering, University of Pretoria, Pretoria, South Africa. Tel.: +27 12420 2172; fax: +27 12362 5000. E-mail: derik.leroux@up.ac.za

${ }^{1}$ This work was done while the author was a Visiting Professor at the University of Pretoria, South Africa. E-mail: padhi@aero.iisc.ernet.in
} 
to an industrial semi-autogenous (SAG) mill in Craig and MacLeod $(1995,1996)$, and the linear model predictive control for an industrial ball mill circuit in Chen et al. (2007).

A robust non-linear model predictive controller (RNMPC) was proposed by Coetzee et al. (2010) to control a ROM ore milling circuit. Full state feedback was assumed. Simulation showed the RNMPC competently controlling the milling circuit's product quality in the presence of typical disturbances such as ore hardness and ore feed size distribution variations. Although the circuit's throughput was included as a controlled variable, independent control of product fineness and throughput was not achieved. Because the computational power required for the RNMPC exceeds what is normally available in industrial installations, the controller is not yet viable for on-line industrial implementation. Alternative structures reducing the computational burden are therefore critical for industrial MPC applications (Qin and Badgwell, 2003; Xi et al., 2013).

The set-point tracking model predictive static programming (MPSP) control approach of le Roux et al. (2014) aims to overcome the computational burden of solving the non-linear minimisation problem of MPC. In their simulation study, where full state feedback was assumed, independent regulation of throughput and product fineness was not achieved, but the computational time was significantly reduced. Although MPSP is a possible alternative for on-line implementation of non-linear model predictive control (NMPC), the minimisation routine of MPSP assumes the problem is unconstrained in terms of the input and output. Box constraints can be applied to the inputs, but these constraints are not explicitly included within the minimisation routine. Further research is required to develop MPSP for set-point tracking problems with input and output constraints.

\subsection{State Estimation}

The use of model-based controllers is preferred over traditional PID controllers for grinding mill circuits (Niemi et al., 1997; Pomerleau et al., 2000; Ramasamy et al., 2005). However, apart from the issue of computational time, the use of model-based controllers in industrial circuits are impeded by the lack of adequate plant measurements to estimate states and parameters for state feedback. Hodouin (2011) describes how the peripheral tools of a control loop are as important as the controller itself to successfully control and optimise a mineral processing plant. The peripheral tools include disturbance observers for external disturbance rejection (Olivier et al., 2012a), model-plant mismatch detection (Olivier and Craig, 2013), and state and parameter estimation (Olivier et al., 2012b).

Currently, the extended Kalman filter (EKF) is the most common choice for estimation in mineral processing plants (Bouche et al., 2005). However, during linearization it is necessary to assume all higher order terms are close to zero and the linearization around the current operating point will ensure convergence with the omission of the higher order terms. If these two requirements do not hold concurrently it could result in divergence even for a system as simple as $y=x^{2}$ (Van der Merwe, 2004).

A particle filter does not suffer from the disadvantage of the EKF in that even highly non-linear nonGaussian models can be used. A particle filter was successfully applied to a grinding mill circuit in simulation in Olivier et al. (2012b) to estimate the mill states. A comparison between EKF and particle filtering for grinding mill circuits can be seen in Cuevas and Cipriano (2008).

\subsection{Contribution}

The novel contribution of this paper is a control architecture using state estimation that can independently regulate product quality and throughput. This is in contrast to Coetzee et al. (2010) and le Roux et al. (2014) where full state feedback was assumed and independent regulation of quality and throughput was not achieved. Independent regulation of quality and throughput is achieved in this paper by using the percentage of critical mill speed as an additional independent manipulated variable (assuming the mill is fitted with a variable speed drive (VSD)). The control architecture incorporates a state estimator for feedback to the controller. Even though comprehensive measurements are generally not available at industrial circuits, the estimator makes use of on-line measurements commonly found at industrial grinding mill circuits (Wei and Craig, 2009b). To address the issue of computational time, a combination of NMPC and dynamic inversion (DI) control is used, the former for plant-wide control and the latter for sump slurry volume control. 


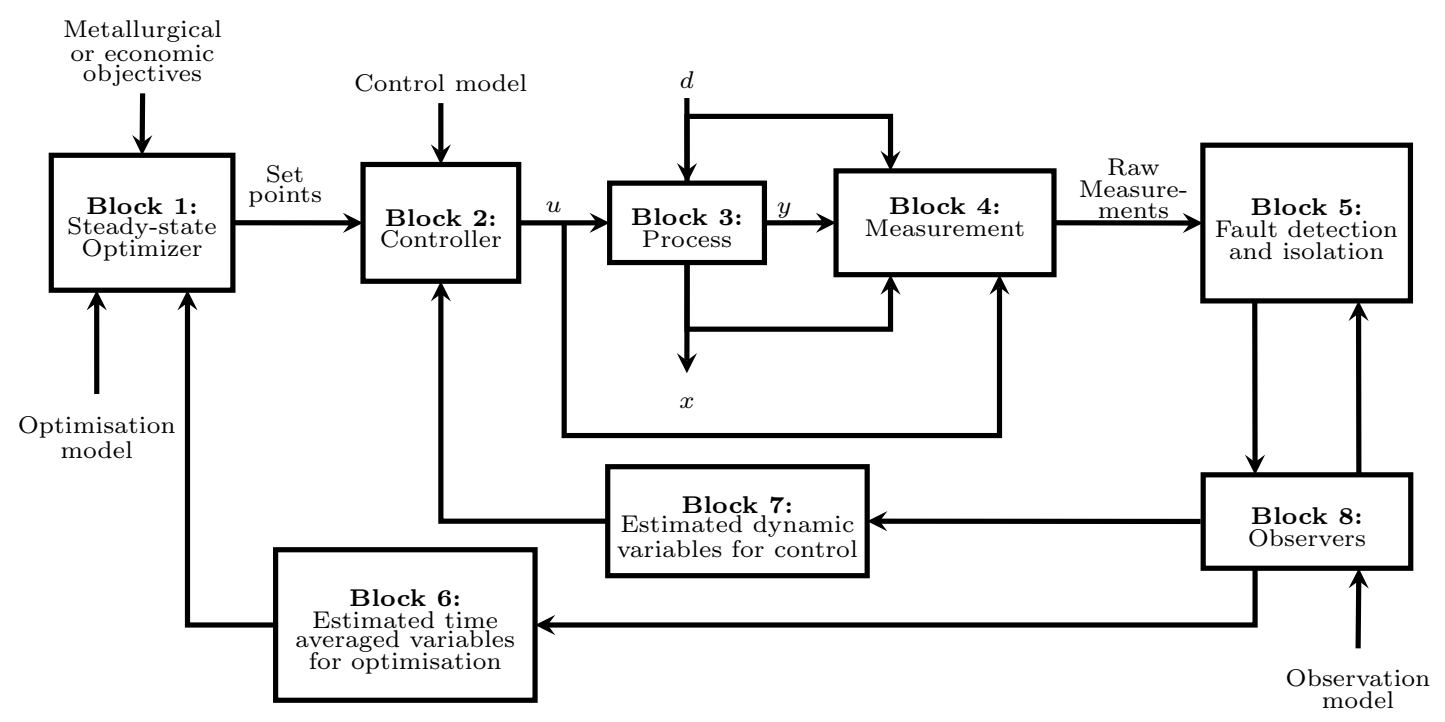

Figure 1: Generalised control loop for mineral processing (from Hodouin (2011)).

This paper builds on the particle filter state estimator of Olivier et al. (2012b) to estimate the states representing the contents of the grinding mill. Olivier et al. (2012b) assumed on-line measurements at the inflow and discharge of the mill. Because measurements at the mill discharge are rarely possible in practice, this paper proposes a state estimator for the mill states relying on measurements that are readily available on industrial plants. In addition, the RNMPC of Coetzee et al. (2010) and the MPSP of le Roux et al. (2014) considers the milling circuit as a whole, and does not make use of the fact that the sump dynamics are much faster than the mill dynamics. In this paper the sump controller is decoupled from the milling circuit controller to make use of this difference in the dynamics of the circuit.

A quantitative comparison of the controller presented in this study and other MPC controllers is beyond the scope of this study. As reference, Wei and Craig (2009a) compared the economic performance of threesingle loop PID controllers to an NMPC using the same plant model as presented here.

The generalised control loop shown in Fig. 1 was developed by Hodouin (2011) for mineral processing and is helpful to understand the structure and aim of this article. The figure illustrates the flow of data between the controller (Block 2), the process (Block 3), and the peripheral tools. The process (Block 3) is described in Section 2 and the process model in Section 3. The controller (Block 2) is formulated in Section 4 and the state estimation strategy (Blocks 7 and 8) in Section 5. Although steady-state optimization (Blocks 1 and 6) is not considered in this study, a strategy for optimization of power consumption, material cost and production time using the same process model is shown in Matthews and Craig (2013). Fault detection and isolation (Block 5) is also not considered in this study. A review of fault detection and isolation can be seen in Venkatasubramanian et al. (2003). Finally, Section 6 shows the simulated results of the controller applied to the milling circuit described by Block 3. Conclusions are discussed in Section 7.

\section{Process description}

The single-stage closed ROM ore milling circuit considered in this study is shown in Fig. 2 and constitute a SAG mill with an end-discharge grate, a sump and a hydrocyclone. The mill receives four streams as inputs: mined ore, water to assist with material transport, steel balls to assist with ore breakage, and underflow from the hydrocyclone. This study assumes that a VSD fitted on the mill motor can be used to manipulate the mill speed allowing improved control of the product particle size (Viklund et al., 2006). The mill motor power draw serves as an indication of the energy required to lift the mill charge. The ground ore in the mill mixes with the water to form a slurry and is discharged from the mill to the sump through 


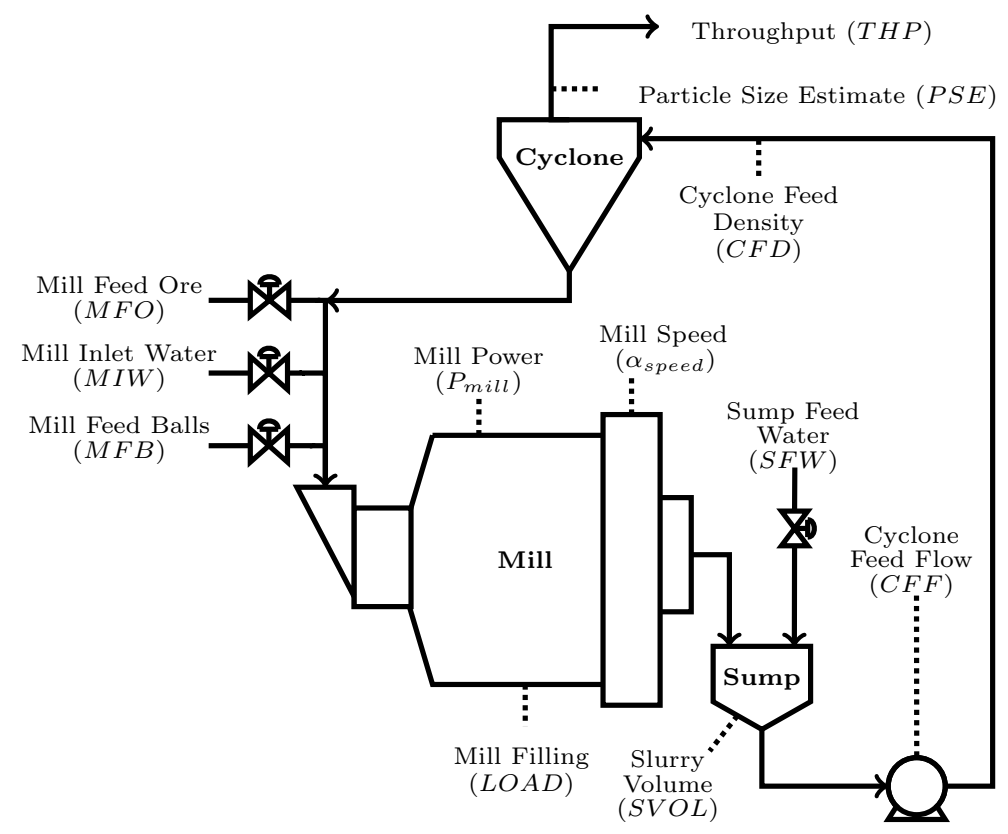

Figure 2: Single-stage closed ROM ore milling circuit.

an end-discharge grate. The slurry in the sump is diluted with water and is pumped to the hydrocyclone for classification. It is assumed the pump is fitted with a variable speed motor to manipulate the cyclone feed flow-rate. The cyclone feed density can be adjusted by the sump dilution water as long as the sump does not overflow or run dry. The hydrocyclone is responsible for the separation of the in-specification and out-of-specification ore discharged from the sump. The lighter, smaller and in-specification particles in the slurry pass to the overflow of the hydrocyclone, while the heavier, larger and out-of-specification particles pass to the underflow. The underflow is passed to the mill for further grinding while the overflow flows to a downstream process. The volumetric flow-rate of solids in the overflow is the throughput of the circuit and is equal to the volumetric feed rate of ore at steady-state operation of the circuit. The quality of the

Table 1: Variables for the run-of-mine ore milling circuit.

\begin{tabular}{lll}
\hline Variable & Description & Unit \\
\hline \multicolumn{2}{l}{ Manipulated variables } & \\
\hline$M I W$ & Mill inlet water flow-rate & {$\left[\mathrm{m}^{3} / \mathrm{h}\right]$} \\
$M F O$ & Mill feed-rate of ore & {$[\mathrm{t} / \mathrm{h}]$} \\
$M F B$ & Mill feed-rate of balls & {$[\mathrm{t} / \mathrm{h}]$} \\
$\alpha_{\text {speed }}$ & Fraction of critical mill speed & {$[$ Fraction $]$} \\
$S F W$ & Sump feed water flow-rate & {$\left[\mathrm{m}^{3} / \mathrm{h}\right]$} \\
$C F F$ & Cyclone feed flow-rate & {$\left[\mathrm{m}^{3} / \mathrm{h}\right]$} \\
\hline Controlled variables & \\
\hline$L O A D$ & Fraction of mill filled & {$\left[\mathrm{Fraction}^{2}\right]$} \\
$P S E$ & Product particle size & {$\left[\mathrm{Fraction}_{2}<75 \mu \mathrm{m}\right]$} \\
$T H P$ & Volumetric throughput of solids & {$\left[\mathrm{m}^{3} / \mathrm{h}\right]$} \\
$S V O L$ & Slurry volume in sump & {$\left[\mathrm{m}^{3}\right]$} \\
\hline Measured variables & \\
\hline$C F D$ & Cyclone feed density & {$\left[\mathrm{t} / \mathrm{m}^{3}\right]$} \\
$P$ mill & Power draw of the mill motor & {$[\mathrm{kW}]$} \\
\hline
\end{tabular}


circuit product is indicated by the fraction of particles in the overflow smaller than specification size. The manipulated, measured and controlled variables mentioned above are shown in Table 1 and are common to most industrial milling plants (Wei and Craig, 2009b).

\section{Process model}

The continuous time dynamic phenomenological non-linear population balance model validated by le Roux et al. (2013) is used in this study to describe the circuit shown in Fig. 2. Each process unit in the circuit is modelled separately. The approach in developing the model was to produce reasonably accurate model responses using as few parameters and states as possible and makes the model ideal for control purposes.

The model divides the ore into three size classes: rocks, coarse ore and fine ore. Rocks are classified as ore too large to pass through the mill discharge grate. Coarse ore can pass through the mill discharge grate but is larger than the specification size. Fine ore also passes through the mill discharge grate but is within specification size. The sum of coarse and fine ore is defined as solids. Although only three size classes are used to describe the ore in the circuit, they are sufficient for the model to produce qualitatively accurate responses (le Roux and Craig, 2013).

The model defines fives states to describe the mill charge volumetric hold-ups: water $\left(X_{m w}\right)$, solids $\left(X_{m s}\right)$, fines $\left(X_{m f}\right)$, rocks $\left(X_{m r}\right)$, and steel balls $\left(X_{m b}\right)$. Because of the mill discharge grate, only three states are necessary to describe the sump slurry volumetric hold-ups: water $\left(X_{s w}\right)$, solids $\left(X_{s s}\right)$, and fines $\left(X_{s f}\right)$. The states of the mill and sump are not measured and need to be estimated.

For the population balance model equations, $V$ denotes a flow-rate in $\mathrm{m}^{3} / \mathrm{h}$ and $X$ denotes the states of the model as volumes in $\mathrm{m}^{3}$. Table 2 provides a description of the subscripts for $V$ and $X$. The first subscript indicates the module considered (mill, sump or cyclone), the second subscript specifies which state is considered (rocks, solids, coarse, fines, balls, or water), and in the case of flow-rates the final subscript indicates an inflow, outflow or underflow. Only a brief overview of the model is presented here. A detailed description of the model is provided in le Roux et al. (2013). The model nomenclature is shown in Table 3.

\subsection{Mill model}

The population volume balance of mill hold-ups - water $\left(X_{m w}\right)$, solids $\left(X_{m s}\right)$, fines $\left(X_{m f}\right)$, rocks $\left(X_{m r}\right)$, and steel balls $\left(X_{m b}\right)$ - are defined in terms of the inflow, outflow and generation/consumption of each state

$$
\begin{aligned}
\dot{X}_{m w} & =V_{m w i}+V_{c w u}-V_{m w o} \\
\dot{X}_{m s} & =V_{m s i}+V_{c s u}-V_{m s o}+R C \\
\dot{X}_{m f} & =V_{m f i}+V_{c f u}-V_{m f o}+F P \\
\dot{X}_{m r} & =V_{m r i}-R C \\
\dot{X}_{m b} & =V_{m b i}-B C
\end{aligned}
$$

where $V_{m w i}, V_{m s i}, V_{m f i}, V_{m r i}$ and $V_{m b i}\left(\mathrm{~m}^{3} / \mathrm{h}\right)$ are the flow-rates of water, solids, fines, rocks and balls into the mill respectively, $V_{m w o}, V_{m s o}$ and $V_{m f_{o}}\left(\mathrm{~m}^{3} / \mathrm{h}\right)$ are the discharge flow-rates of water, solids and fines respectively, $R C, B C$ and $F P\left(\mathrm{~m}^{3} / \mathrm{h}\right)$ are the rock consumption, ball consumption and fines production respectively, and $V_{c w u}, V_{c s u}$ and $V_{c f u}\left(\mathrm{~m}^{3} / \mathrm{h}\right)$ represent the cyclone water, solids and fines underflow flowrates respectively.

Table 2: Description of subscripts

\begin{tabular}{ll}
\hline Subscript & Description \\
\hline$X_{\square-}$ & m-mill; s-sump; c-cyclone \\
$X_{-\square}$ & w-water; s-solids; c-coarse; f-fines; r-rocks; b-balls \\
$V_{--} \square$ & i-inflow; o-outflow; u-underflow \\
\hline
\end{tabular}




\subsubsection{Mill feed}

The flow of material into the mill is defined as

$$
\begin{aligned}
V_{m w i} & =M I W \\
V_{m s i} & =\left(1-\alpha_{r}\right) M F O / \rho_{S} \\
V_{m f i} & =\alpha_{f} M F O / \rho_{S} \\
V_{m r i} & =\alpha_{r} M F O / \rho_{S} \\
V_{m b i} & =M F B / \rho_{B}
\end{aligned}
$$

where $M I W\left(\mathrm{~m}^{3} / \mathrm{h}\right)$ is the mill inlet water flow-rate, $M F O(\mathrm{t} / \mathrm{h})$ is the mill feed-rate of ore, $M F B(\mathrm{t} / \mathrm{h})$ is the mill feed-rate of steel balls, $\rho_{S}\left(\mathrm{t} / \mathrm{m}^{3}\right)$ is the approximate ore density, $\rho_{B}\left(\mathrm{t} / \mathrm{m}^{3}\right)$ is the ball density, and parameters $\alpha_{f}$ and $\alpha_{r}$ represent the fraction of fines and rocks in $M F O$ respectively. Although $M F O$ in

\begin{tabular}{|c|c|c|}
\hline Parameter & Value & Description \\
\hline \multicolumn{3}{|c|}{ Mill parameters } \\
\hline$\alpha_{f}$ & 0.055 & Fraction of fines in the feed ore \\
\hline$\alpha_{r}$ & 0.465 & Fraction of rocks in the feed ore \\
\hline$\alpha_{P}$ & 1 & Fractional power reduction per fractional reduction of critical mill speed \\
\hline$\alpha_{\varphi_{f}}$ & 0.01 & Fractional change in $\mathrm{kW} /$ fines produced per change in fractional filling of mill \\
\hline$\chi_{P}$ & 0 & Cross-term for maximum power draw \\
\hline$\delta_{P s}$ & 2.898 & Power-change parameter for fraction solids in the mill \\
\hline$\delta_{P v}$ & 2.898 & Power-change parameter for volume of mill filled \\
\hline$d_{0}$ & 84.5 & Discharge rate $\left[\mathrm{h}^{-1}\right]$ \\
\hline$\varepsilon_{s v}$ & 0.6 & Max fraction of solids by volume slurry at zero slurry flow \\
\hline$\varphi_{P_{\max }}$ & 0.57 & Rheology factor for maximum mill power draw \\
\hline$\phi_{b}$ & 90 & Steel abrasion factor $[\mathrm{kWh} / \mathrm{t}]$ \\
\hline$\phi_{f}$ & 31.31 & Power needed per ton of fines produced $[\mathrm{kWh} / \mathrm{t}]$ \\
\hline$\phi_{r}$ & 8.06 & Rock abrasion factor $[\mathrm{kWh} / \mathrm{t}]$ \\
\hline$\rho_{S}$ & 3.2 & Density of ore $\left[\mathrm{t} / \mathrm{m}^{3}\right]$ \\
\hline$\rho_{B}$ & 7.85 & Density of balls $\left[\mathrm{t} / \mathrm{m}^{3}\right]$ \\
\hline$\rho_{W}$ & 1 & Density of water $\left[\mathrm{t} / \mathrm{m}^{3}\right]$ \\
\hline$v_{P_{\max }}$ & 0.34 & Fraction of mill volume filled for maximum power draw \\
\hline$v_{\text {mill }}$ & 59.1 & Mill volume $\left[\mathrm{m}^{3}\right]$ \\
\hline \multicolumn{3}{|c|}{ Hydrocyclone parameters } \\
\hline$\alpha_{s u}$ & 1.497 & Parameter related to fraction solids in underflow \\
\hline$\varepsilon_{s}$ & 111.85 & Parameter related to coarse split $\left[\mathrm{m}^{3} / \mathrm{h}\right]$ \\
\hline$C_{1}$ & 0.6 & Constant \\
\hline$C_{2}$ & 0.7 & Constant \\
\hline$C_{3}$ & 4 & Constant \\
\hline$C_{4}$ & 4 & Constant \\
\hline$C_{5}$ & 0.6 & Constant \\
\hline
\end{tabular}
an industrial plant can be controlled fairly well, variations in feed size distribution (represented by $\alpha_{r}$ and $\alpha_{f}$ ) upset the equilibrium in a mill considerably and impede maintaining a mill in the optimum operating region.

Table 3: Nomenclature. (Dimensionless parameters are shown without units.) 


\subsubsection{Mill discharge}

The mill discharge flow-rates are defined as

$$
\begin{gathered}
V_{m w o}=\varphi d_{0} X_{m w}\left(\frac{X_{m w}}{X_{m s}+X_{m w}}\right) \\
V_{m s o}=\varphi d_{0} X_{m w}\left(\frac{X_{m s}}{X_{m s}+X_{m w}}\right) \\
V_{m f o}=\varphi d_{0} X_{m w}\left(\frac{X_{m f}}{X_{m s}+X_{m w}}\right)
\end{gathered}
$$

where $d_{0}(1 / \mathrm{h})$ is the discharge rate, and $\varphi$ is an empirical function called the rheology factor. The rheology factor attempts to incorporate the effect of the fluidity and density of the slurry on the milling circuit's performance and is defined as

$$
\varphi=\max \left[0,\left(1-\left(\frac{1}{\varepsilon_{s v}}-1\right) \frac{X_{m s}}{X_{m w}}\right)^{0.5}\right]
$$

where $\varepsilon_{s v}$ is the maximum fraction of solids by volume of slurry at zero slurry flow. A rheology factor of unity corresponds to $\frac{X_{m s}}{X_{m w}}=0$ indicating the slurry consists only of water. A rheology factor of zero corresponds to $\frac{X_{m s}}{X_{m w}}=\frac{\varepsilon_{s v}}{1-\varepsilon_{s v}}$ indicating the slurry is a non-flowing mud.

\subsubsection{Material consumption and production}

The general formulation of the breakage equations has its parallel in the cumulative breakage rates expressions in Hinde and Kalala (2009) and Amestica et al. (1996). The rock consumption $(R C)$, ball consumption $(B C)$ and fines production $(F P)$ are defined as

$$
\begin{aligned}
R C & =\frac{\varphi P_{m i l l} X_{m r}}{\rho_{S} \phi_{r}\left(X_{m r}+X_{m s}\right)} \\
B C & =\frac{\varphi P_{m i l l} X_{m b}}{\phi_{b}\left[\rho_{S}\left(X_{m r}+X_{m s}\right)+\rho_{B} X_{m b}\right]} \\
F P & =\frac{P_{m i l l}}{\rho_{S} \phi_{f}\left[1+\alpha_{\phi_{f}}\left(L O A D-v_{P_{\text {max }}}\right)\right]}
\end{aligned}
$$

where $\phi_{r}$ and $\phi_{b}(\mathrm{kWh} / \mathrm{t})$ are the abrasion rates of rocks and balls respectively, $\phi_{f}(\mathrm{kWh} / \mathrm{t})$ is the energy required per tonne of fines produced, $v_{P_{\max }}$ is the fraction of the mill filled at maximum power draw, $\alpha_{\phi_{f}}$ accounts for the change in $\phi_{f}$ per change in mill filling, and $P_{\text {mill }}$ is the mill power draw. The equilibrium of the mill is not only upset through variations of the feed size distribution, but also variations in ore hardness. This can be simulated through variation of parameters $\phi_{f}$ and $\phi_{r}$.

\subsubsection{Mill load and power draw}

The fraction of the mill filled with charge $(L O A D)$ is defined as

$$
L O A D=\left(X_{m w}+X_{m s}+X_{m r}+X_{m b}\right) / v_{m i l l}
$$

where $v_{\text {mill }}\left(\mathrm{m}^{3}\right)$ is the total volume of the mill.

The mill power draw is modelled as a quadratic function depending on the total mill charge and the fluidity and density of the slurry in the mill

$$
P_{\text {mill }}=P_{\text {max }}\left(\alpha_{\text {speed }}\right)^{\alpha_{P}}\left(1-\delta_{P v} Z_{x}^{2}-2 \chi_{P} \delta_{P v} \delta_{P s} Z_{x} Z_{r}-\delta_{P s} Z_{r}^{2}\right)
$$

where $P_{\max }(\mathrm{kW})$ is the maximum mill power draw, $\alpha_{\text {speed }}$ is the fraction of critical mill speed, $\alpha_{P}$ is the fractional power reduction per fractional reduction from critical mill speed, $\delta_{P v}$ is the power change 
parameter for volume of mill filled, $\delta_{P s}$ is the power change parameter for the fraction of solids in the mill, and $\chi_{P}$ is the cross term for maximum power draw. The parabolic shape of mill power draw as a function of mill load is further discussed in Powell et al. (2009).

The effect of the total charge on mill power is modelled by the empirical definition of $Z_{x}=\frac{L O A D}{v_{P_{\max }}}-1$, and the effect of the solids content on the mill power is modelled by the empirical definition of $Z_{r}=\frac{\varphi}{\varphi_{P \max }}-1$ where $\varphi_{P_{\max }}$ is the rheology factor at maximum mill power draw.

\subsection{Sump model}

The population volume balance of sump hold-ups - water $\left(X_{s w}\right)$, solids $\left(X_{s s}\right)$, and fines $\left(X_{s f}\right)$ - are defined as

$$
\begin{aligned}
\dot{X}_{s w} & =V_{m w o}-V_{s w o}+S F W \\
\dot{X}_{s s} & =V_{m s o}-V_{s s o} \\
\dot{X}_{s f} & =V_{m f o}-V_{s f o}
\end{aligned}
$$

where $V_{\text {swo }}, V_{\text {sso }}$ and $V_{\text {sfo }}\left(\mathrm{m}^{3} / \mathrm{h}\right)$ are the sump discharge flow-rates of water, solids and fines respectively, and $S F W\left(\mathrm{~m}^{3} / \mathrm{h}\right)$ is the sump feed water flow-rate. It is assumed the slurry in the sump is fully mixed.

\subsubsection{Sump discharge}

The discharge of each state from the sump through the variable speed pump is defined as

$$
\begin{aligned}
V_{s w o} & =C F F \frac{X_{s w}}{X_{s w}+X_{s s}} \\
V_{s s o} & =C F F \frac{X_{s s}}{X_{s w}+X_{s s}} \\
V_{s f o} & =C F F \frac{X_{s f}}{X_{s w}+X_{s s}}
\end{aligned}
$$

where $C F F\left(\mathrm{~m}^{3} / \mathrm{h}\right)$ is the cyclone feed flow-rate.

\subsubsection{Slurry volume and cyclone feed density}

The volume of the sump filled with slurry $(S V O L)\left(\mathrm{m}^{3}\right)$ and the cyclone feed density $(C F D)\left(\mathrm{t} / \mathrm{m}^{3}\right)$ are defined as

$$
\begin{aligned}
S V O L & =X_{s s}+X_{s w} \\
C F D & =\frac{\rho_{W} V_{\text {swo }}+\rho_{S} V_{\text {sso }}}{V_{\text {swo }}+V_{\text {sso }}}
\end{aligned}
$$

where $\rho_{W}$ is the density of water.

\subsection{Hydrocyclone model}

\subsubsection{Underflow and overflow}

Static non-linear models in the form of efficiency curves are used to model a number of classification units in minerals processing (Nageswararao et al., 2004). The non-linear static cyclone model presented here aims to model the product size and density by taking the effects of angular velocity of the particle inside the cyclone, the slurry density and slurry viscosity into account. The underflow of coarse material $\left(V_{c c u}\right)$ $\left(\mathrm{m}^{3} / \mathrm{h}\right)$ is modelled as

$$
V_{c c u}=\left(V_{s s o}-V_{s f o}\right)\left(1-C_{1} \exp \left(\frac{-C F F}{\varepsilon_{c}}\right)\right)\left(1-\left(\frac{F_{i}}{C_{2}}\right)^{C_{3}}\right)\left(1-P_{i}^{C_{4}}\right)
$$


where $F_{i}=\frac{V_{s s o}}{C F F}$ is the fraction solids in the cyclone feed, $P_{i}=\frac{V_{s f o}}{V_{s s o}}$ is the fraction fines in the feed solids, $\varepsilon_{c}$ $\left(\mathrm{m}^{3} / \mathrm{h}\right)$ relates to the coarse split, $C_{1}$ relates to the split at low-flows when the centrifugal force on particles is relatively small, $C_{2}$ normalizes the fraction solids in the feed according to the upper limit for the packing fraction of solid particles, and $C_{3}$ and $C_{4}$ adjusts the sharpness of the dependency on $F_{i}$ and $P_{i}$.

To determine the amount of water and fines accompanying the coarse underflow, the fraction of solids in the underflow $\left(F_{u}\right)$ must be determined. This is modelled as

$$
F_{u}=C_{5}-\left(C_{5}-F_{i}\right) \exp \left(-V_{c c u} /\left(\alpha_{s u} \varepsilon_{c}\right)\right)
$$

where $C_{5}$ is the approximate maximum packing fraction, and $\alpha_{s u}$ relates to the fraction solids in the underflow.

The cyclone underflow flow-rates (as shown in (1)) are defined as

$$
\begin{aligned}
V_{c w u} & =\frac{V_{s w o}\left(V_{c c u}-F_{u} V_{c c u}\right)}{F_{u} V_{s w o}+F_{u} V_{s f o}-V_{s f o}} \\
V_{c f u} & =\frac{V_{s f o}\left(V_{c c u}-F_{u} V_{c c u}\right)}{F_{u} V_{s w o}+F_{u} V_{s f o}-V_{s f o}} \\
V_{c s u} & =V_{c c u}+V_{c f u} .
\end{aligned}
$$

These equations follow from the assumption that the fines are not influenced by centrifugal forces. This implies the ratio of fines to water in the overflow, underflow and feed is equal, and that the fraction of solids in the underflow can be written as $F_{u}=\frac{V_{c s u}}{V_{c s u}+V_{c w u}}$. Consequently, the cyclone water overflow flow-rate $\left(V_{c w o}\right)$, solids overflow flow-rate $\left(V_{c s o}\right)$ and fines overflow flow-rate $\left(V_{c f o}\right)$ can be calculated using a flow balance around the cyclone.

\subsubsection{Product quality and throughput}

The product quality is defined as the fraction of fines to solids in the cyclone overflow, and is represented by the particle size estimate $(P S E)$. The product throughput $(T H P)\left(\mathrm{m}^{3} / \mathrm{h}\right)$ is defined as the volumetric flow of solids in the cyclone overflow.

$$
\begin{aligned}
P S E & =\frac{V_{c f o}}{V_{c s o}} \\
T H P & =V_{c s o}
\end{aligned}
$$

\subsection{Process Model}

The $\boldsymbol{P}$ lant model can be represented in non-linear state-space as

$$
\begin{aligned}
& \dot{\mathbf{x}}_{P}(t)=\mathbf{f}_{P}\left(t, \mathbf{x}_{P}, \mathbf{u}_{P}\right) \\
& \mathbf{y}_{P}(t)=\mathbf{g}_{P}\left(t, \mathbf{x}_{P}, \mathbf{u}_{P}\right)
\end{aligned}
$$

where $\mathbf{x}_{P}$ represents the plant's state variables, $\mathbf{y}_{P}$ represents the plant's measured variables, and $\mathbf{u}_{P}$ represents the plant's manipulated variables. The states, the manipulated variables and measured variables are

$$
\begin{aligned}
& \mathbf{x}_{P}=\left[X_{m w}, X_{m s}, X_{m f}, X_{m r}, X_{m b}, X_{s w}, X_{s s}, X_{s f}\right]^{T} \\
& \mathbf{u}_{P}=\left[M I W, M F O, M F B, \alpha_{\text {speed }}, C F F, S F W\right]^{T} \\
& \mathbf{y}_{P}=\left[L O A D, P_{m i l l}, S V O L, C F D, P S E, T H P\right]^{T} .
\end{aligned}
$$

Function $\mathbf{f}_{P}$ is given by (1) and (10), and function $\mathbf{g}_{P}$ is given by (8), (9), (12), (13), (17) and (18). 




Figure 3: Block diagram illustrating the control configuration implemented. (Variables $L O A D^{*}, P S E^{*}, T H P^{*}$ and $X_{s w}^{*}$ in the figure indicate the set-points of the respective variables.)

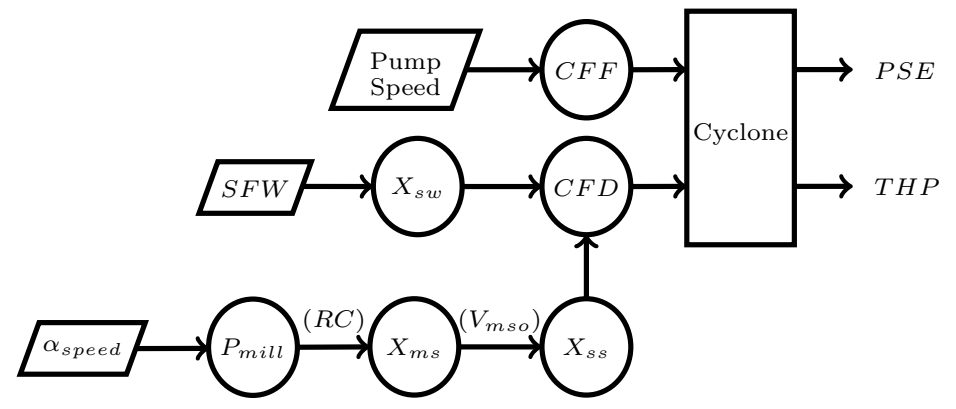

Figure 4: Conceptual block diagram illustrating manipulated variables for independent control of $T H P$ and $P S E$.

\section{Control Architecture}

The grinding mill circuit shown in Fig. 2 is a mixture of both fast and slow dynamics. The time constant for the dynamics of $M F O$ to $P S E$ is in the range of $30 \mathrm{~min}$, whereas the time constant of $C F F$ to $P S E$ is in the range of 2 min. Also, the mill exhibits slow integrating dynamics compared to the sump's fast integrating action. If, for example, the difference between $C F F$ and $S F W$ is $300 \mathrm{~m}^{3} / \mathrm{h}$, a sump with $5 \mathrm{~m}^{3}$ of slurry could potentially run dry within 1 min (Coetzee et al., 2010). Because the slow and fast dynamics are clearly separable in the circuit, a fast acting controller with low processing requirements can be used for the sump while an optimizing controller with a greater processing burden can be used for the remainder of the circuit.

The chosen control architecture is depicted in Fig. 3 and consists of DI control coupled with NMPC. A DI controller is chosen to manage the fast dynamics of the sump allowing more time for NMPC to determine the optimal trajectories of the remaining variables. Instead of two isolated controllers, the closed-form solution produced by the DI controller is used by the NMPC.

Since the cyclone model in Section 3.3 and the mill power draw model in Section 3.1.4 are static nonlinear equations, linearisation will reduce the models to constant gains only accurate in a small region around the operating point. Non-linear control is therefore justified since it has the advantage of directly using the static non-linear models as internal prediction models to ensure accurate results over a larger operating window. Also, as seen in the system identification of an industrial single-stage closed grinding mill circuit by Craig and MacLeod (1995), the uncertainties in linear transfer function elements can range from $10 \%$ to $65 \%$.

For a degree of independent control of $T H P$ and $P S E$, it is necessary to evaluate which manipulated 
variables are most suitable as control handles for THP and PSE. The following discussion is done with reference to the conceptual block diagram in Fig. 4. Manipulation of $C F D$ and $C F F$ allows control of $P S E$ and THP. The $C F F$ can be manipulated through the VSD of the sump pump. The $C F D$ is a function of the sump states $X_{s w}$ and $X_{s s}$, and manipulation of either sump state can be used to achieve a desired $C F D$. $X_{s w}$ can easily be manipulated at the sump through $S F W$, whereas $X_{s s}$ is not so easily manipulated. $X_{s s}$ is determined by the grinding efficiency of the mill and cannot be changed at the sump. To increase $X_{s s}$ more solids need to be produced and discharged by the mill. This can be achieved by using $\alpha_{\text {speed }}$ as a manipulated variable to vary $P_{\text {mill }}$ in (9). An increase in $P_{\text {mill }}$ will result in an increase in the generation of solids through $R C$ in (5), a subsequent increase in $X_{m s}$ through (1b), an increase in the discharge flow-rate $V_{m s o}$ in (3b), and finally to the increase of $X_{s s}$ through (10b). Not only will this increase in $X_{s s}$ cause an increase in $C F D$, it can also allow for an increase in $T H P$ as more solids are available to be discharged from the circuit. Using $\alpha_{\text {speed }}$ as manipulated variable therefore allows further control over THP.

As shown in Fig. 3, the NMPC uses the manipulated variables $M I W, M F O, M F B, \alpha_{\text {speed }}, C F F$, and $X_{s w}$ to achieve the desired $L O A D, T H P$, and $P S E$ set-points. The NMPC therefore feeds $X_{s w}$ as a set-point to the DI controller. The DI controller controls $X_{s w}$ via $S F W$. This is done because of the dependence of PSE and THP on $X_{s w}$ via $C F D$, and the ease with which $X_{s w}$ can be controlled by manipulating $S F W$. The variation range of $X_{s w}$ is bound by the limits of $S V O L$ to ensure the sump does not run dry or overflow. Since $S V O L$ has no steady-state impact on the circuit performance, no set-point is specified. The only requirement is that it remains within its constraints.

In this section, the overall control objectives are summarised in Section 4.1, the NMPC is discussed in Section 4.2, and the DI controller in Section 4.3.

\subsection{Control objectives}

The control objectives considered in this paper are

1. tracking of set-points with independent control of PSE and THP, and

2. compensation for model-plant mismatch.

\subsection{Non-linear model predictive control (NMPC)}

\subsubsection{Continuous and Discrete Model}

The $\boldsymbol{C}$ ontroller model can be represented in continuous-time state-space as

$$
\begin{aligned}
& \dot{\mathbf{x}}_{C}(t)=\mathbf{f}_{C}\left(t, \mathbf{x}_{C}, \mathbf{u}_{C}\right) \\
& \mathbf{y}_{C}(t)=\mathbf{g}_{C}\left(t, \mathbf{x}_{C}, \mathbf{u}_{C}\right) .
\end{aligned}
$$

As illustrated in Fig. 3, the states, the manipulated variables and controlled variables used by the NMPC model are

$$
\begin{aligned}
& \mathbf{x}_{C}=\left[X_{m w}, X_{m s}, X_{m f}, X_{m r}, X_{m b}, X_{s s}, X_{s f}\right]^{T} \\
& \mathbf{u}_{C}=\left[M I W, M F O, M F B, \alpha_{\text {speed }}, C F F, X_{s w}\right]^{T} \\
& \mathbf{y}_{C}=[L O A D, P S E, T H P]^{T}
\end{aligned}
$$

where function $\mathbf{f}_{C}$ is given by (1) and (10b)-(10c), and function $\mathbf{g}_{C}$ is given by (8), (17) and (18). (Eq. (10a) is not included in function $\mathbf{f}_{C}$ since it is a controlled variable.)

The trapezoidal rule is used to derive the discrete form of function $\mathbf{f}_{C}$ :

$$
\mathbf{x}_{k+1}=\mathbf{x}_{k}+\frac{1}{2} h\left[\mathbf{f}_{C}\left(t(k+1), \mathbf{x}_{C}, \mathbf{u}_{C}\right)+\mathbf{f}_{C}\left(t(k), \mathbf{x}_{C}, \mathbf{u}_{C}\right)\right]
$$

where $h$ is the step size, and the subscript $C$ is removed from the discrete controller model variables for the sake of simplicity. The equation above can be solved for $\mathbf{x}_{k+1}$ using the Newton-Raphson method:

$$
\mathbf{x}_{k+1}^{i}=\mathbf{x}_{k+1}^{i-1}-\left[I-\left.\frac{1}{2} \frac{\partial \mathbf{f}_{C}}{\partial \mathbf{x}}\right|_{\mathbf{x}_{k+1}, \mathbf{u}_{k+1}}\right]^{-1} \psi\left(\mathbf{x}_{k+1}^{i-1}, \mathbf{x}_{k}, \mathbf{u}_{k+1}, \mathbf{u}_{k}\right)
$$


where $i$ is the iteration index, and

$$
\psi\left(\mathbf{x}_{k+1}^{i-1}, \mathbf{x}_{k}, \mathbf{u}_{k+1}, \mathbf{u}_{k}\right)=\mathbf{x}_{k+1}-\mathbf{x}_{k}-\frac{1}{2} h\left[\mathbf{f}_{C}\left(t(k+1), \mathbf{x}_{C}, \mathbf{u}_{C}\right)+\mathbf{f}_{C}\left(t(k), \mathbf{x}_{C}, \mathbf{u}_{C}\right)\right] .
$$

The discrete model for the controller is represented in non-linear state-space as

$$
\begin{aligned}
& \mathbf{x}_{k+1}=\mathbf{f}_{C_{k}}\left(\mathbf{x}_{k}, \mathbf{u}_{k}\right) \\
& \mathbf{y}_{k}=\mathbf{g}_{C_{k}}\left(\mathbf{x}_{k}, \mathbf{u}_{k}\right) .
\end{aligned}
$$

\subsection{2. $N M P C$ Cost Function}

Given the discrete model in (26), the aim of the controller can be described as

$$
\begin{array}{ll} 
& \min J\left(\mathbf{u}_{k}, \ldots, \mathbf{u}_{k+N_{c}-1}, \mathbf{x}_{k}\right) \\
\text { s.t. } & \mathbf{u}_{k+1}, \ldots, \mathbf{u}_{k+N_{c}-1}=\mathbf{f}_{C_{k}}\left(\mathbf{x}_{k}, \mathbf{u}_{k}\right) \\
& \mathbf{y}_{k}=\mathbf{g}_{C_{k}}\left(\mathbf{x}_{k}, \mathbf{u}_{k}\right) \\
& \mathbf{u}_{l} \leq \mathbf{u}_{k} \leq \mathbf{u}_{u} \\
& \Delta \mathbf{u}_{l} \leq \Delta \mathbf{u}_{k} \leq \Delta \mathbf{u}_{u} \\
& \mathbf{y}_{l} \leq \mathbf{y}_{k} \leq \mathbf{y}_{u}
\end{array}
$$

where the objective function $J$ is defined as

$$
J(\cdot)=\sum_{i=0}^{N_{p}-1}\left(\mathbf{y}_{s p}-\mathbf{y}_{k+i \mid k}+D\right)^{T} \mathbf{Q}_{1}\left(\mathbf{y}_{s p}-\mathbf{y}_{k+i \mid k}+D\right)+\sum_{i=0}^{N_{c}-1}\left(\Delta \mathbf{u}_{k+i \mid k}\right)^{T} \mathbf{Q}_{2}\left(\Delta \mathbf{u}_{k+i \mid k}\right)
$$

with $\mathbf{y}_{s p}$ the controlled variable set-points, $N_{p}$ the prediction horizon and $N_{c}$ the control horizon.

The constant term $D=\hat{\mathbf{y}}_{k}-\mathbf{y}_{k}$ is included to add integral action to the controller, where $\hat{\mathbf{y}}_{k}$ is the plant output and $\mathbf{y}_{k}$ is the model output at $t(k)$. As noted by Meadows and Rawlings (1997), this conventional feedback procedure assumes the difference between the process and model outputs is a result of additive step disturbances which persist throughout the prediction horizon. The method corresponds to adding a bias to the controller prediction. Although simplistic, this method of integral action has the advantage of accurately modelling set-point changes which enter the feedback loop as step disturbances, approximating slowly varying model mismatch errors, and zero offset for step changes in the set-point. However, this method can be sensitive to random fluctuations in the output.

There is no direct penalty on the input terms in the MPC formulation as contradictory goals may arise. At steady-state $T H P$ is equal to the $M F O$. If sufficient ore is available, then $T H P$ can be increased as long as $P S E$ is maintained at the increased $T H P$. Minimisation of $M F O$ as an input is then contradictory to the goal of increasing $T H P$ as these two are equal at steady-state. Rather, the rate of change of the manipulated variables are penalised as this reduces high energy expenditure to make changes in the manipulated variables.

The upper and lower constraints for the controlled variables $\left(\mathbf{y}_{u}\right.$ and $\left.\mathbf{y}_{l}\right)$ and the manipulated variables $\left(\mathbf{u}_{u}\right.$ and $\left.\mathbf{u}_{l}\right)$ are shown in Table 4 . The aim of the manipulated and controlled variables' constraints is to maintain the circuit within an operable region. Since the plant model provides the equality between the manipulated and controlled variables, the states are assumed to remain within operable bounds if the manipulated and controlled variables are within bounds. State constraints are therefore not included in the MPC formulation. The tuning parameters for the NMPC are the weighting matrices $\mathbf{Q}_{1}$ for the controlled variables and $\mathbf{Q}_{2}$ for the rate of change in the manipulated variables, as are discussed next.

\subsubsection{Controller Weights}

Since PSE and THP determine the economic efficiency of the circuit, it is desired to have tighter control of these controlled variables compared to $L O A D$. Therefore, the weighting matrix $\mathbf{Q}_{1}=\operatorname{diag}\left\{q_{11}, q_{12}, q_{13}\right\}$ for the output variables was determined such that a $0.5 \%$ deviation from set-point for THP will produce 
an error in the cost function equal to a $1 \%$ deviation of PSE from set-point and a $10 \%$ deviation of $L O A D$ from set-point, i.e.

$$
q_{11}\left(10 \% L O A D_{S P}\right)^{2}=q_{12}\left(0.5 \% T H P_{S P}\right)^{2}=q_{13}\left(1 \% P S E_{S P}\right)^{2}
$$

The weighting matrix $\mathbf{Q}_{2}=\operatorname{diag}\left\{q_{21}, q_{22}, \ldots, q_{26}\right\}$ for the input variables was determined such that $1 \%$ change of half the ranges of $C F F$ and $X_{s w}$ will produce the same error as $2 \%$ change of half the ranges of $M I W$ and $M F O$, and as $15 \%$ change of half the ranges of $\alpha_{\text {speed }}$ and $M F B$. The aim is to use less of $\alpha_{\text {speed }}$ and $M F B$ to achieve set-point as these variables can affect power consumption dramatically. Care should be taken not to increase $M I W$ too quickly as this could wash out the fines in the mill and drop the mill power draw very quickly. As shown in Craig et al. (1992a), effective use of $M I W$ can improve the range of control of $P S E$. The input weighting matrix is

$$
\begin{aligned}
& q_{21}\left(2 \% M I W_{\text {range }} / 2\right)^{2}=q_{22}\left(2 \% M F O_{\text {range }} / 2\right)^{2}=q_{23}\left(15 \% M F B_{\text {range }} / 2\right)^{2}= \\
& q_{24}\left(15 \% \alpha_{\text {speed }_{\text {range }}} / 2\right)^{2}=q_{25}\left(1 \% C F F_{\text {range }} / 2\right)^{2}=q_{26}\left(1 \% X_{\text {swange }} / 2\right)^{2}
\end{aligned}
$$

The $\mathbf{Q}_{2}$ matrix is scaled to produce $1 \%$ of the error in $J$ compared to the $\mathbf{Q}_{1}$ matrix, and is also scaled with the ratio between the control and prediction horizon, i.e.

$$
q_{21}\left(2 \% M I W_{\text {range }} / 2\right)^{2}=100 q_{11} \frac{N_{p}}{N_{c}}\left(10 \% L O A D_{S P}\right)^{2}
$$

\subsection{Dynamic inversion (DI)}

As shown in Fig. 3, the NMPC demands a specific value of $X_{s w}$ to minimise the cost function in (28). Because of its simple design structure, DI is chosen to control $X_{s w}$ through the manipulation of $S F W$. DI control operates on the principle that the output error dynamics are enforced as a stable linear system. After selecting an appropriate form for the error dynamics, usually in PID form, the control is computed by inverting the system dynamics. If the non-linear system dynamics are available, the DI controller realisation is preferable over a PID realisation. This is because the DI method leads to a closed form solution for the controller, guarantees asymptotic stability of the error dynamics, and is easy to implement online (Enns et al., 1994; Teo et al., 2009).

Dynamic inversion allows the specification of a desired response path by choosing a proportional gain value $\left(K_{p}\right)$ and an integral gain value $\left(K_{I}\right)$ such that:

$$
e K_{p}+K_{I} \int_{0}^{t} e d \tau+\dot{e}=0
$$

where $e=\hat{y}-y_{s p}$ is the difference between the measured value $(\hat{y})$ and the set-point $\left(y_{s p}\right)$.

\subsubsection{Synthesis of $S F W$ and Constraint handling}

Control of $X_{s w}$ cannot be done without consideration of physical bounds imposed by the sump. SVOL should not reduce to zero or exceed the total volume of the sump. The constraints of $S V O L$ is incorporated in the control of $X_{s w}$ through the function illustrated in Fig. 5. In the 'safe' region between lower bound $\left(S_{L B}\right)$ and upper bound $\left(S_{U B}\right)$ there is no concern of the sump overflowing or running dry. In this region the controller can focus on meeting the set-point of $X_{s w}$ through manipulation of $S F W$. As $S V O L$ approaches critical operational constraints $\left(S_{\min }\right.$ or $\left.S_{\max }\right)$ manipulated variable $S F W$ is used to bring $S V O L$ back to the 'safe' region. This can be compared to error-squared control (Seborg et al., 2004).

The manipulated variable, $S F W$, is the synthesis of $S F W_{X_{s w}}$ and $S F W_{S V O L}$ through a convex combination

$$
S F W=(1-\lambda) S F W_{X_{s w}}+\lambda S F W_{S V O L}
$$

where $S F W_{X_{s w}}$ denotes the case where $X_{s w}$ is the main target of the controller, and $S F W_{S V O L}$ denotes the case where the sump slurry is in danger of violating the constraints on $S V O L$. In other words, $S F W$ is 


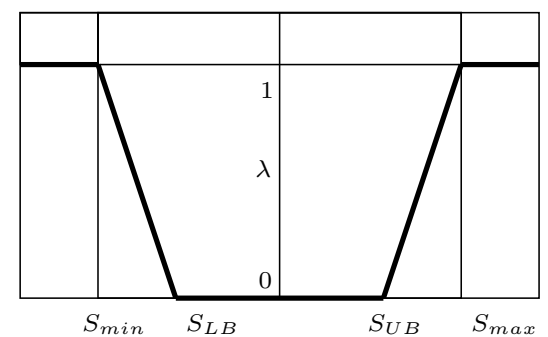

Figure 5: Conceptual figure illustrating convex combination.

determined from the requirements for the water fraction in the sump slurry and the constraints of the sump slurry volume. The function $\lambda$, illustrated in Fig. 5, is defined as

$$
\lambda= \begin{cases}1 & ; \quad S V O L<S_{\min } \\ \overline{S_{\min }-S_{L B}}\left(S V O L-S_{L B}\right) & ; \quad S_{\min } \leq S V O L \leq S_{L B} \\ 0 & ; \quad S_{L B}<S V O L<S_{U B} \\ \overline{S_{\max }-S_{U B}}\left(S V O L-S_{U B}\right) & ; \quad S_{U B} \leq S V O L \leq S_{\max } \\ 1 & ; \quad S V O L>S_{\max }\end{cases}
$$

For $S F W_{S V O L}$, the error in the controller equation (32) is defined as

$$
e=\Delta S V O L=\left\{\begin{array}{lll}
S V O L-S_{U B} & ; \quad S V O L \leq\left(S_{L B}+S_{U B}\right) / 2 \\
S V O L-S_{L B} & ; \quad S V O L>\left(S_{L B}+S_{U B}\right) / 2
\end{array}\right.
$$

such that

$$
\frac{d}{d t}(\Delta S V O L)+K_{p 1}(\Delta S V O L)+K_{I 1} \int_{0}^{t}(\Delta S V O L) d \tau=0 .
$$

For $S F W_{X_{s w}}$, the error in the controller equation (32) is defined as $e=\Delta X_{s w}=X_{s w}-X_{s w}^{*}$ where $X_{s w}^{*}$ is the set-point and $X_{s w}$ is the current state. Thus

$$
\frac{d}{d t}\left(\Delta X_{s w}\right)+K_{p 2}\left(\Delta X_{s w}\right)+K_{I 2} \int_{0}^{t}\left(\Delta X_{s w}\right) d \tau=0 .
$$

From the differentiation and subsequent simplification of $S V O L$ in (12), it is possible to simplify (35) to

$$
S F W_{S V O L}=\left(C F F-V_{m w o}-V_{m s o}\right)-K_{p 1}(\Delta S V O L)-K_{I 1} \int_{0}^{t}(\Delta S V O L) d \tau .
$$

Using (10a), it is possible to simplify (36) to

$$
S F W_{X_{s w}}=V_{s w o}-V_{m w o}-K_{I 2} \int_{0}^{t}\left(\Delta X_{s w}\right) d \tau-K_{p 2}\left(\Delta X_{s w}\right) .
$$

\section{State estimation}

As seen from Wei and Craig (2009b), the measurements available on industrial grinding mill circuits are limited. Full-state feedback to the controller is not possible as the modelled states cannot be measured directly. State estimation is done separately for the mill and sump because the mill and sump states are distinct by definition.

The particle filter method of Olivier et al. (2012b) is used for the estimation of all five mill states. However, to use this method it is necessary to inferentially determine the mill discharge flow-rates as industrial mills have no direct measurements of these variables. The only measurement of mill contents available at 




Figure 6: Block diagram illustrating the estimation configuration.

the mill is $L O A D$. Fortunately, if the sump states are known, it is possible to determine the mill discharge flow-rates $V_{m w o}, V_{m s o}$ and $V_{m f o}$ by means of a flow balance over the sump. The sump states are readily observable from the measurable variables $S V O L, C F F, C F D$ and $P S E$. The next two subsections describe the process followed to estimate the sump states through algebraic equations and the mill states using a particle filter. The estimation process is illustrated in Fig. 6.

\subsection{State estimation of the sump states}

The $C F F$ is given by

$$
C F F=V_{\text {swo }}+V_{\text {sso }} \text {. }
$$

Assuming the total mass of slurry in the sump is given by $M_{T}=M_{S}+M_{W}$ where $M_{S}$ is the mass of solids and $M_{W}$ is the mass of water, (39) can be written as

$$
\frac{M_{T}}{C F D}=\frac{M_{S}}{\rho_{S}}+\frac{M_{W}}{\rho_{W}} .
$$

Therefore, (40) can be simplified to give the solid mass fraction

$$
\frac{M_{S}}{M_{T}}=\frac{\frac{1}{C F D}-1}{\frac{1}{\rho_{S}}-1} .
$$

From the result above, the estimates of the sump water volume $\left(\hat{X}_{s w}\right)$ and solids volume $\left(\hat{X}_{s s}\right)$ can be expressed in terms of measured quantities as

$$
\begin{aligned}
& \hat{X}_{s w}=\frac{S V O L \cdot C F D}{\rho_{W}}\left(1-\frac{\frac{1}{C F D}-1}{\frac{1}{\rho_{S}}-1}\right) \\
& \hat{X}_{s s}=S V O L\left(\frac{1-C F D}{1-\rho_{S}}\right) .
\end{aligned}
$$

Because the fraction of fines in the sump outflow is not measured, the measurement of PSE has to be used for the estimate of the sump fines volume $\left(\hat{X}_{s f}\right)$. By writing PSE in (17) in terms of the sump states and $C F F$, it is possible to solve numerically for $\hat{X}_{s f}$. 


\subsection{State estimation of the mill states}

The particle filter of Olivier et al. (2012b) is used to provide mill state estimates for water $\left(\hat{X}_{m w}\right)$, solids $\left(\hat{X}_{m s}\right)$, fines $\left(\hat{X}_{m f}\right)$, rocks $\left(\hat{X}_{m r}\right)$ and balls $\left(\hat{X}_{m b}\right)$. Only a brief description of the particle filter implementation is given here and further details can be found in Olivier et al. (2012b).

\subsubsection{Particle filter formulation}

Particle filtering is a technique that implements a recursive Bayesian filter using Monte Carlo simulations. It relies on the technique of representing the posterior probability density function, which is used for estimation, by a set of random samples and associated weights. The locations of the particles represent the locations at which the probability density function is evaluated and the sizes of the particles represent the associated weights, giving an indication of the value of the probability density function at this location. This representation is expandable to an arbitrary number of dimensions and is applicable to any distribution, even multi-modal and other non-Gaussian distributions. As the number of particles becomes very large, this method of representing the probability density function becomes equivalent to the functional description of the posterior probability density function.

Let $y_{0: k}=\left\{y_{0}, \ldots, y_{k}\right\}$ represent the sequence of all measurements up to the current time, then the general state estimation problem is formulated as the solution of the conditional distribution function $p\left(x_{k} \mid y_{0: k}\right)$, which is the distribution of the state given all the observations up to time $t(k)$. The probability density function at $t(k)$ may then be approximated as

$$
p\left(x_{k} \mid y_{0: k}\right) \approx \sum_{i=1}^{N_{s}} w_{k}^{i} \delta\left(x_{k}-x_{k}^{i}\right)
$$

where $N_{s}$ is the number of particles and $\left\{x_{k}^{i}, w_{k}^{i}\right\}_{i=1}^{N_{s}}$ is the set of particles and associated weights (Arulampalam et al., 2002). These weights are defined to be

$$
w_{k}^{i} \propto w_{k-1}^{i} \frac{p\left(y_{k} \mid x_{k}^{i}\right) p\left(x_{k}^{i} \mid x_{k-1}^{i}\right)}{r\left(x_{k}^{i} \mid x_{k-1}^{i}, y_{k}\right)}
$$

where $r\left(x_{k}^{i} \mid x_{k-1}^{i}, y_{k}\right)$ is a proposal distribution called an importance density. Ideally the importance density should be the true posterior distribution $p\left(x_{k} \mid y_{k}\right)$, but this is generally not known. Instead, the transitional prior is used as the proposal distribution because of the ease of implementation and good accuracy (Ristic et al., 2004), i.e. $r\left(x i_{t} \mid x_{k-1}^{i}, y_{k}\right)=p\left(x_{k} \mid x_{k-1}^{i}\right)$. This is a sufficiently accurate suboptimal choice when a more complex importance density is not warranted. If the process noise is assumed to be additive zero-mean Gaussian noise, the transitional prior becomes

$$
p\left(x_{k} \mid x_{k-1}^{i}\right)=\mathcal{N}\left(x_{k}: f_{k}\left(x_{k-1}^{i}\right), R_{k-1}\right)
$$

where $R_{k}$ is the noise standard deviation. This assumption also means that particles can be drawn from the Gaussian distribution

$$
x_{k}^{i} \sim \mathcal{N}\left(f_{k}\left(x_{k-1}^{i}\right), R_{k-1}\right) .
$$

The assumption of Gaussian noise simplifies the particle filter implementation, although it is not generally required in the particle filtering framework.

The variance of the importance weights can only increase over time (Douchet et al., 2000). This means that after only a couple of iteration steps all but one particle will have negligible normalized weights. This effect is known as degeneracy. Degeneracy is eliminated through the use of resampling to eliminate the particles with low importance weights and multiplies particles with high importance weights. The algorithm uses the cumulative sum of weights defined as

$$
\bar{W}_{i}=\sum_{j=1}^{i} w_{k}^{j}
$$

and draws samples from $u \in[0,1]$ to map new samples from $\bar{W}$. The pseudo-code for the resampling routine is provided in Algorithm 1 (Arulampalam et al., 2002). 


\subsubsection{Particle filter implementation}

A sequential importance resampling (SIR) particle filter is used and the pseudo-code for this filter is shown in Algorithm 2 (Arulampalam et al., 2002). The inputs $\left(\mathbf{u}_{P F}\right)$ and outputs $\left(\mathbf{y}_{P F}\right)$ necessary for the particle filter to determine the five mill states are

$$
\begin{aligned}
& \mathbf{u}_{P F}=\left[M I W, M F O, M F B, \alpha_{\text {speed }}, V_{c w u}, V_{c s u}, V_{c f u}\right]^{T} \\
& \mathbf{y}_{P F}=\left[V_{\text {mwo }}, V_{\text {mso }}, V_{\text {mfo }}, L O A D, P_{\text {mill }}\right]^{T} .
\end{aligned}
$$

Using (16), the cyclone underflows can be determined from the estimated sump states $\hat{X}_{s w}, \hat{X}_{s s}$ and $\hat{X}_{s f}$ (see Section 5.1). The mill discharge flow-rates $V_{m w o}, V_{m s o}$ and $V_{m f o}$ are not measured directly and are calculated using the sump population balance equations in (10). Therefore,

$$
\begin{aligned}
V_{m w o} & =\frac{d}{d t} \hat{X}_{s w}+C F F \frac{\hat{X}_{s w}}{S V O L}-S F W \\
V_{m s o} & =\frac{d}{d t} \hat{X}_{s s}+C F F \frac{\hat{X}_{s s}}{S V O L} \\
V_{m f o} & =\frac{d}{d t} \hat{X}_{s f}+C F F \frac{\hat{X}_{s f}}{S V O L}
\end{aligned}
$$

where derivatives of the sump state estimates can be determined using for example a Savitzky-Golay filter if a time-series of estimates is available (Savitzky and Golay, 1964). The uncertainty in the sump estimates is assumed to appear as white noise at the particle filter, and is therefore absorbed in the formulation of the particle filter.

Similarly to the NMPC, the particle filter is based on a discrete model. The Trapezoidal rule and Newton-Raphson method as described in Section 4.2.1 are used to discretize and propagate the model. The state-space model for the particle filter is the five mill state equations in (1). The output equations are given by (3), (8) and (9).

\section{Simulation and results}

\subsection{Simulation environment}

Table 4 shows the initial conditions of the variables and states for the simulations. The setup of the general simulation environment is as follows:

Table 4: Initial conditions, limits (Min, Max), and rate constraints $(\Delta)$ of the plant described in Section 3.

\begin{tabular}{lccccl}
\hline Var & Value & Min & Max & $\Delta$ & Unit \\
\hline \multicolumn{5}{c}{ Manipulated Variables } \\
\hline$M I W$ & 4.71 & 0 & 40 & 2 & {$\left[\mathrm{~m}^{3} / \mathrm{h}\right]$} \\
$M F O$ & 66.9 & 0 & 100 & 1 & {$[\mathrm{t} / \mathrm{h}]$} \\
$M F B$ & 6.43 & 0 & 15 & 0.5 & {$[\mathrm{t} / \mathrm{h}]$} \\
$\alpha_{\text {speed }}$ & 0.72 & 0.6 & 0.85 & 0.01 & {$[-]$} \\
$C F F$ & 267 & 200 & 450 & 5 & {$\left[\mathrm{~m}^{3} / \mathrm{h}\right]$} \\
$S F W$ & 67.1 & 0 & 300 & - & {$\left[\mathrm{m}^{3} / \mathrm{h}\right]$} \\
\hline \multicolumn{6}{c}{ Measured Variables } \\
\hline LOAD & 0.31 & 0.2 & 0.4 & - & {$[-]$} \\
$P S E$ & 0.60 & 0.5 & 0.8 & - & {$[-]$} \\
THP & 20.9 & 15 & 30 & - & {$\left[\mathrm{m}^{3} / \mathrm{h}\right]$} \\
$S V O L$ & 10.0 & 2.5 & 17 & - & {$\left[\mathrm{m}^{3}\right]$} \\
$P_{m i l l}$ & 1142 & - & - & - & {$\left[\mathrm{kW}^{3}\right]$} \\
$C F D$ & 1.79 & - & - & - & {$\left[\mathrm{t} / \mathrm{m}^{3}\right]$} \\
\hline \multicolumn{7}{c}{ States } & & \\
\hline$X_{m w}$ & 3.78 & - & - & - & {$\left[\mathrm{m}^{3}\right]$} \\
$X_{m s}$ & 3.45 & - & - & - & {$\left[\mathrm{m}^{3}\right]$} \\
$X_{m f}$ & 1.08 & - & - & - & {$\left[\mathrm{m}^{3}\right]$} \\
$X_{m r}$ & 1.86 & - & - & - & {$\left[\mathrm{m}^{3}\right]$} \\
$X_{m b}$ & 9.23 & - & - & - & {$\left[\mathrm{m}^{3}\right]$} \\
$X_{s w}$ & 6.43 & 2.5 & 17 & - & {$\left[\mathrm{m}^{3}\right]$} \\
$X_{s s}$ & 3.57 & - & - & - & {$\left[\mathrm{m}^{3}\right]$} \\
$X_{s f}$ & 1.12 & - & - & - & {$\left[\mathrm{m}^{3}\right]$} \\
\hline
\end{tabular}


(i.) The total simulation time is $7 \mathrm{~h}$.

(ii.) The states of the plant as given by (19) is integrated over each time interval $t=(k-1) T_{s}$ to $t=k T_{s}$ using the explicit fourth order Runge-Kutta method at a sampling time of $T_{s}=10 \mathrm{~s}$.

(iii.) The manipulated variables determined by the NMPC are implemented at intervals of $60 \mathrm{~s}$ because of the slow mill dynamics. The fmincon function with the $s q p$ algorithm in MATLAB ${ }^{2}$ R2015a is used to minimize the cost function. Section 4.2.1 describes the discrete model used for the NMPC algorithm. (The Newton-Raphson method used to solve for $\mathbf{x}_{k+1}$ in (24) is terminated if the answer to (25) is smaller than $10^{-5}$ ).

(iv.) The manipulated variable constraints and maximum allowable rate of change are shown in Table 4. These constraints are applied in the minimization routine. Note that $X_{s w}$ is seen as a manipulated variable by the NMPC, which is why a minimum and maximum constraint appears for this state in Table 4.

(v.) The DI control manipulated variable is updated every 10 seconds. The quicker sampling rate compared to the NMPC is because of the fast sump dynamics.

(vi.) Measurement noise with a normal distribution of $\mathcal{N}\left(0, \sigma^{2}\right)$ is added to the controlled and measured variables listed in Table 5 . The standard deviation is shown in Table 5 as a percentage of the initial variable set-point. State noise is not added to the simulation environment. If state noise is added it is necessary to differentiate between the cumulative effect of the state and measurement noise when evaluating the controller and estimator performance. Since only the measurements are used by the controller and estimator, the noise added to the measurements are regarded as sufficient to account for model uncertainty. This also simplifies deductions that can be made from the results.

(vii.) A particle filter with 1000 particles is used. The initial estimates of the mill states are randomly selected from a region $( \pm 10 \%)$ around the actual initial state values. The a priori density function $p\left(x_{k} \mid x_{k-1}\right)$ is assumed to be normal with a standard deviation of 0.02 . The likelihood function $p\left(y_{k} \mid x_{k}\right)$ is assumed to be normal with a standard deviation of 0.1 .

\subsubsection{Noise filters}

The measurement noise added to the variables listed in Table 5 results in a deterioration of the sump and mill state estimates. A Savitzky-Golay digital filter (Savitzky and Golay, 1964) was designed to filter the noise of the measurements used for estimation. The filter smooths data by fitting successive sub-sets of $F$ data samples with low-degree polynomials of order $N$ by means of linear least squares. The filter returns the filtered value at the centre of the frame. The advantage of this filter is that it does not introduce a phase shift in the data. However, for a real-time application the filter design needs to be adapted to return the filtered value at the end of the frame which corresponds to the most recent measurement. The following filter design procedure was used:

(i.) For a frame size of $F$ samples, construct a vector $z_{i}=[-F+1,-F+2, \ldots, 0]^{T}$.

(ii.) For a polynomial of degree $N$ construct the matrix $J_{i, j+1}=z_{i}^{j}$ for $i=1 \ldots F$ and $j=1 \ldots N$.

${ }^{2}$ MATLAB $^{T M}$ is a registered trademark of The Mathworks Inc.

Table 5: Plant measurement noise and parameter uncertainty as percentages of nominal values.

\begin{tabular}{ll|ll}
\hline Var & $\sigma$ & Var & $\sigma$ \\
\hline LOAD & $1 \%$ & SVOL & $0.5 \%$ \\
PSE & $1 \%$ & $P_{\text {mill }}$ & $2 \%$ \\
THP & $1 \%$ & CFD & $1.5 \%$ \\
\hline Parm & $\Delta$ & Parm & $\Delta$ \\
\hline$\alpha_{f}$ & $30 \%$ & $\phi_{f}$ & $20 \%$ \\
$\alpha_{r}$ & $30 \%$ & $\phi_{r}$ & $20 \%$ \\
\hline
\end{tabular}


(iii.) The filter coefficients $C$ are calculated by solving $C=\left(J^{T} J\right)^{-1} J^{T}$. Matrix $C$ will be of size $\mathbb{R}^{(N+1) \times F}$.

(iv.) The filtered data point $Y(k)$ is produced by convolution of the unfiltered data string $y^{\prime}=\{y(k-F+$ $1), \ldots, y(k)\}$ of $F$ samples and the first row of filter coefficients: $Y(k)=C_{1} \otimes y^{\prime}$.

(v.) The approximate of the first order derivative $\dot{Y}(k)$ is produced by convolution of the unfiltered data string $y^{\prime}$ and the second row of filter coefficients $\dot{Y}(k)=C_{2} \otimes y^{\prime}$.

(vi.) For this application the data points $y^{\prime}$ are weighted so that the last data points count more towards the polynomial fit than the first data points. The following weight matrix is used: $W=$ $\operatorname{diag}\left[0,\left(\frac{1}{F-1}\right)^{2},\left(\frac{2}{F-1}\right)^{2}, \ldots, 1\right]$. The filter coefficients are then given by $C=\left(J W^{T} J\right)^{-1} J^{T} W$.

The noise on the measurements is considered as high frequency noise, whereas the dynamics of the system are considered to fall within the low frequency range. The aim of the filter is to reduce the high frequency noise while maintaining the dynamics of the system. Plant measurements were filtered before state estimation with a Savitzky-Golay filter. The filter used a frame length of 37 samples to fit a second order polynomial to the process data. The mill discharge flow-rate estimates in (48) were calculated algebraically as shown in Section 5.1 using the filtered measurement data. The first order derivatives were set to zero because the noise on the signals skews the calculated derivative values. Also, because the variables change relatively slowly, the derivatives are expected to be negligibly small. Since the sump states are not estimated with complete accuracy, uncertainty is propagated and may be accentuated through the algebraic calculation of the inputs and outputs necessary for the particle filter to estimate the mill states. If the measurements are not filtered to reduce the measurement noise, the accuracy of the algebraically calculated sump states, and consequently, the mill state estimates reduces significantly.

\subsubsection{Controller setup}

$N M P C$ - It is generally recommended to choose the prediction horizon $\left(N_{p}\right)$ based on the longest settling time between the manipulated and controlled variables (Seborg et al. (2004)). Assuming a sampling time of $1 \mathrm{~min}$, this results in an impractical $N_{p}>500$ because of the $P S E-\alpha_{\text {speed }}$ interaction. To yield a controller that is feasible to implement a prediction horizon of $N_{p}=18$ (corresponding to $18 \mathrm{~min}$ ) was chosen. A good trade-off between controller aggression and computational expense was found tuning the control horizon to $N_{c}=3$ (corresponding to $3 \mathrm{~min}$ ).

From the bounds and set-points given in Table 4, the weights of the controller can be determined from (29)-(31). Choosing $q_{11}=1$, the matrices are

$$
\begin{aligned}
& \mathbf{Q}_{1}=\operatorname{diag}[1,6.67,0.022] \\
& \mathbf{Q}_{2}=\operatorname{diag}[0.90,0.40,0.11,410,0.092,27.4]
\end{aligned}
$$

$D I$ controller - The bounds for $S V O L$ were chosen as $\left\{S_{\min }, S_{L B}, S_{U B}, S_{\max }\right\}=\{2.5,5,15,17.5\}$ $\mathrm{m}^{3}$. The controller was tuned to $K_{p 1}=10 K_{i 1}=20$ and $K_{p 2}=10 K_{I 2}=20$.

\subsection{Simulation Sets}

The aim of the simulations is to test how well the proposed control-estimation configuration meet the control objectives set in Section 4.1. Two simulation sets are used:

Simulation 1: Independent set-point tracking of PSE and THP.

Set-point changes are made to $P S E$ from 0.60 to 0.65 at $t=1 \mathrm{~h}$, to 0.625 at $t=3 \mathrm{~h}$ and to 0.65 at $t=5 \mathrm{~h}$. THP is stepped from $20.9 \mathrm{~m}^{3} / \mathrm{h}$ to $22.2 \mathrm{~m}^{3} / \mathrm{h}$ at $t=2 \mathrm{~h}$, to $23.2 \mathrm{~m}^{3} / \mathrm{h}$ at $t=4 \mathrm{~h}$, and to $22.7 \mathrm{~m}^{3} / \mathrm{h}$ at $t=6 \mathrm{~h}$. The set-point for $L O A D$ is kept at 0.31 . A first order transfer function with unity gain and a time constant of $3 \mathrm{~min}$ is used to filter set-point changes. No parametric disturbances are applied in this simulation.

Simulation 2: Disturbance rejection.

Any industrial mill has to contend with disturbances to plant operation, of which the most important are disturbances to the feed ore size distribution and the ore hardness. The following disturbances are applied to the plant: 

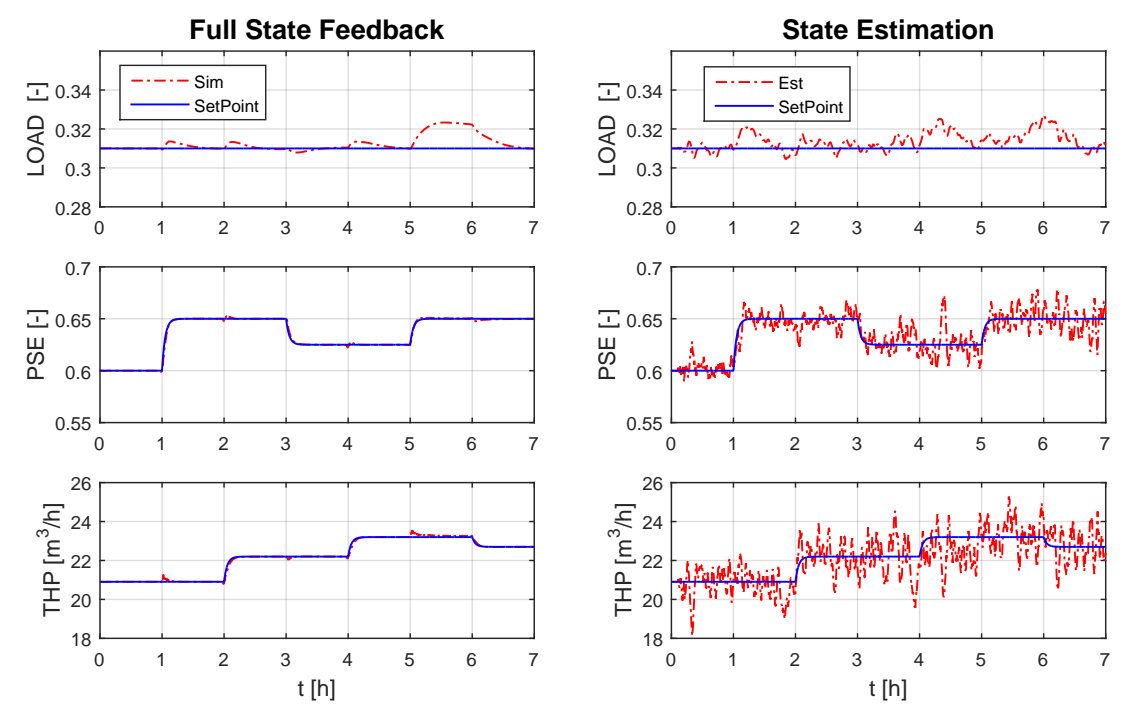

Figure 7: NMPC controlled variables for Simulation 1: fraction of mill filled (LOAD), product quality $(P S E)$ and product throughput $(T H P)$.

(Legend: Sim - simulation with full state feedback; Est - simulation with feedback through estimation; Setpoint - variable set-point.)

(i.) A change in feed size distribution is simulated by applying ramp step-changes to $\alpha_{f}$ and $\alpha_{r}$ at $t=1.5 \mathrm{~h}$ and $t=3.5 \mathrm{~h}$, and back to nominal at $t=5.5 \mathrm{~h}$.

(ii.) A change in feed ore hardness is simulated by applying ramp step-changes to $\phi_{r}$ and $\phi_{f}$ at $t=2.5 \mathrm{~h}$ and $t=4.5 \mathrm{~h}$, and back to nominal at $t=6.5 \mathrm{~h}$.

The disturbances are applied by stepping the parameters around their nominal values (as given in Table 3). The size of the ramp step-changes are randomly selected from the uniform distribution $\mathcal{U}(-\Delta, \Delta)$ where $\Delta$ represents the deviation from the nominal value of a parameter. The deviation as a percentage of the nominal parameter value is shown in Table 5 . The set-points for the circuit are kept constant at $[L O A D, P S E, T H P]^{T}=[0.31,0.60,20.9]^{T}$.

In each simulation setup, the following two scenarios are simulated:

(i.) The first scenario assumes full state feedback to the controller with no measurement noise added to the states.

(ii.) The second scenario adds noise to the measurements and uses the state estimation strategy described in Section 5 for state feedback.

\subsubsection{Simulation 1 Results: Set-point tracking}

Results for Simulation 1 are shown in Figs. 7-9. The main controlled variables are shown in Fig. 7, the circuit's manipulated variables are shown in Fig. 8, and the particle filter estimates of the mill states and the algebraic estimates of the sump states (see Sections 5.1-5.2) are shown in Fig. 9.

As expected, Figs. 7-8 show that for approximate steady-state conditions $T H P$ is equal to $M F O / \rho_{S}$. At $t=4 \mathrm{~h}$ the step in THP causes $\alpha_{\text {speed }}$ to operate at its constraint. However, as seen on the left in Fig. 7 , for the case with full state feedback the controller is still able to maintain the variables at set-point. At $t=5 \mathrm{~h}$ the set-point change in PSE is managed, but $L O A D$ needs to deviate from set-point to allow the increase in PSE. The deviation of $L O A D$ from set-point is expected given the NMPC tuning described in Section 4.2.3.

As shown in Fig. 9, the estimates of water and solids states for the mill and sump are accurate. The fines estimates for the mill and sump are both fairly noisy, but the trends are reasonably well captured. The estimate of $X_{m b}$ captures the correct trend, whereas the estimate of $X_{m r}$ is the least accurate. 

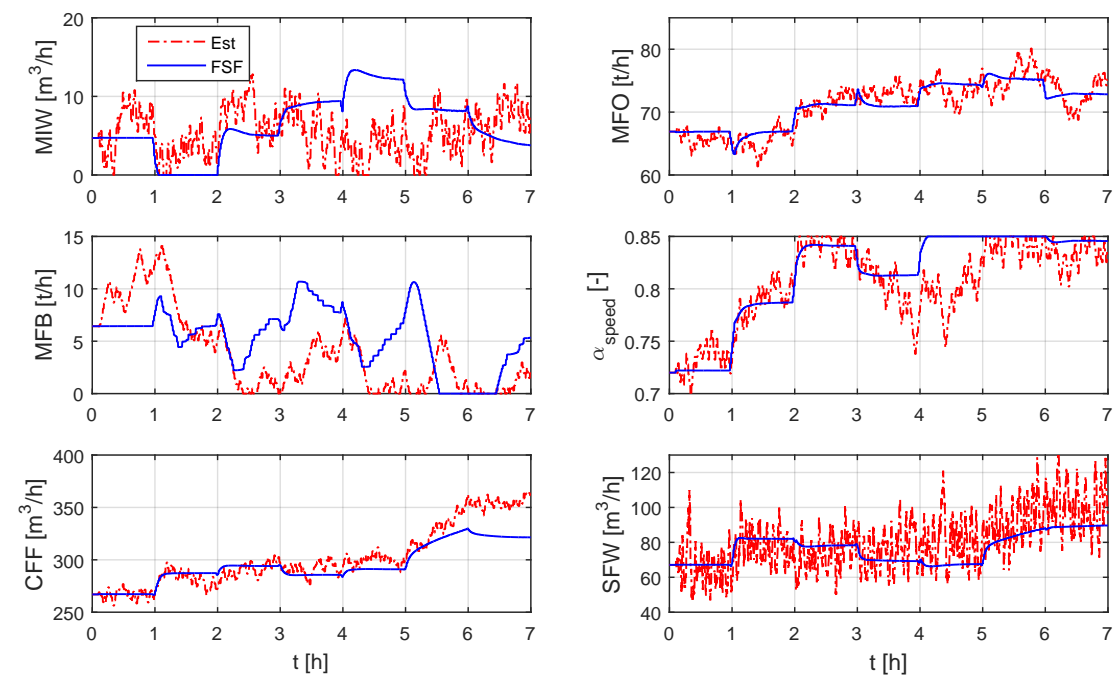

Figure 8: Manipulated variables for Simulation 1: mill inlet water $(M I W)$, mill feed ore $(M F O)$, mill feed balls $(M F B)$, fraction of critical mill speed $\left(\alpha_{\text {speed }}\right)$, cyclone feed flow $(C F F)$, and sump feed water $(S F W)$.

(Legend: Est - feedback through estimation; FSF - full state feedback.)
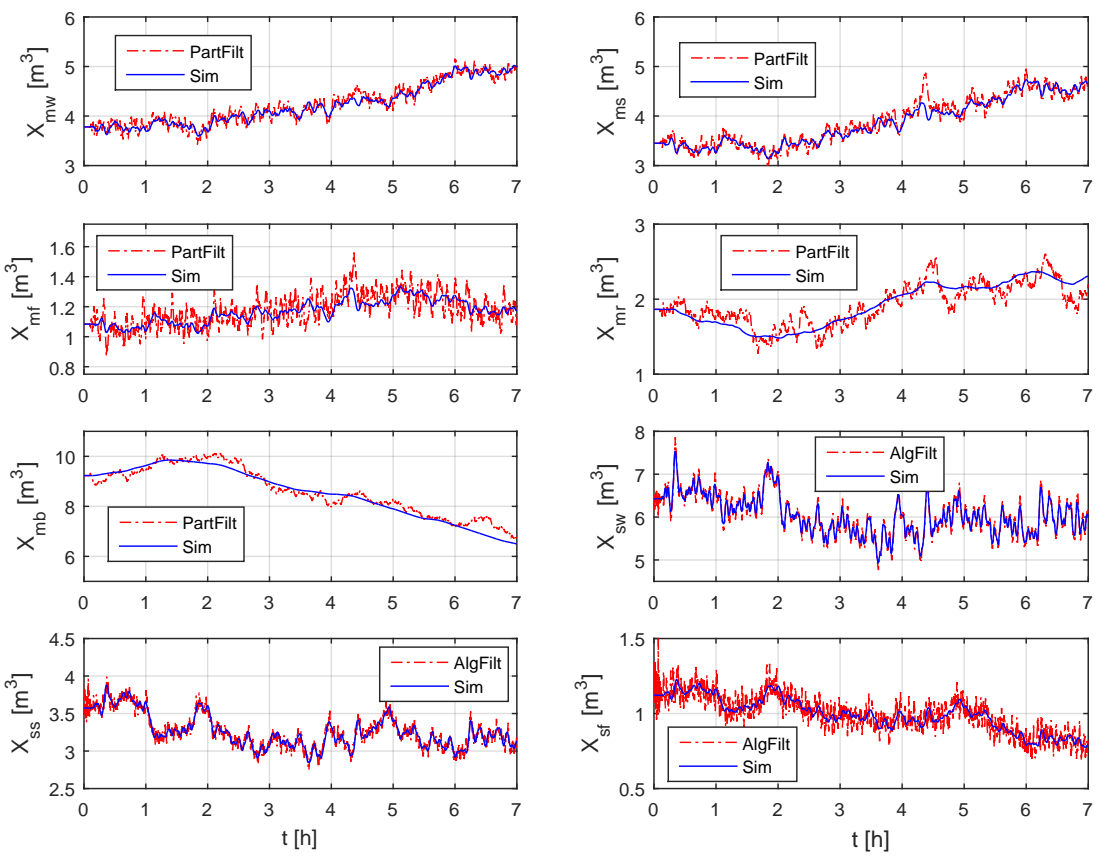

Figure 9: Mill state estimates from particle filter: water $\left(X_{m w}\right)$, solids $\left(X_{m s}\right)$, fines $\left(X_{m f}\right)$, rocks $\left(X_{m r}\right)$ and balls $\left(X_{m b}\right)$. Sump state estimates from algebraic filter: water $\left(X_{s w}\right)$, solids $\left(X_{s s}\right)$ and fines $\left(X_{s f}\right)$.

(Legend: Sim - simulated value; PartFilt - Particle filter estimate; AlgFilt - Algebraic filter estimate.)

For full state feedback the simulated value and not the estimated value is fed back to the NMPC controller. In the case of state estimation for state feedback, the deviation of the controlled variables 
from their set-points in Fig. 7 are a result of the effect of the measurement noise on the consequent state estimation. The states estimated from noisy measurements cause an offset to the estimate of $D$ in (28). In an attempt to reduce the effect of the noise on the estimates, the mean of the past 18 model outputs and plant measurements were used to calculate the vector $D$. Also, the elements in vector $D$ were only applied if its absolute value was larger than $1 \%$ of the set-point (i.e. if $\left|D_{i}\right|=\left|\left(\hat{y}_{1_{i}}-y_{1_{i}}\right)\right| \leq 0.1 y_{s p_{i}}$ then $D_{i}=0$ ).

The simulation can be viewed as a case of disturbance rejection of $L O A D$ as the desired operating point of $L O A D$ ensures the mill is not over-filled, nor under-filled. As shown by Van der Westhuizen and Powell (2006), it is necessary in some cases to allow $L O A D$ to deviate from its desired set-point to achieve a particular $P S E$ or THP. As noted in Section 4.2.3, the weighting on $L O A D$ is relaxed to allow it to vary around its nominal condition.

Table 6 shows the mean, standard deviation and normalised root mean squared error (NRMSE) of the controlled variables for the different set-points. In each case the time period of evaluation is only when the set-point is at steady-state. It takes approximately $0.3 \mathrm{~h}$ for a set-point to settle at a new value. The standard deviation is taken with respect to the set-point for the specific time interval. Although the mean and standard deviation is calculated, the variation of the process signal around the set-point is not necessarily Gaussian. The NMRSE was calculated as

$$
N R M S E=\frac{1}{\bar{\lambda}_{S P}} \sqrt{\frac{\sum^{N}\left(\hat{\lambda}-\lambda_{S P}\right)^{2}}{N}}
$$

where $\lambda_{S P}$ is the desired set-point, $\bar{\lambda}_{S P}$ is the mean of the set-point over the period, $\hat{\lambda}$ is the process signal, and $N$ is the number of data points. Results for the case with full state feedback are good, as would be expected. In the case of state estimation, set-points are achieved with a reasonable degree of accuracy as shown by the mean value achieved over the periods of interest. It is only in the period $4.3 \mathrm{~h}$ to $6 \mathrm{~h}$ that THP is below the desired set-point. For the case of state estimation, the NRMSE of LOAD and PSE is roughly $2 \%$, and the NRMSE for THP around $4 \%$.

Table 7 shows the time for the NMPC calculations and the particle filter calculations. The maximum time for the NMPC to complete a calculation was approximately half a minute. The particle filter needed less than 1 second to complete its calculations. Since the NMPC needs to produce a new input move every minute, the time requirement for the NMPC calculation is easily met. The particle filter needs to provide updates every 10 seconds, and can do so with relative ease. Calculations were completed in MATLAB R2015a on a 64-bit computer with a $3 \mathrm{GHz}$ Intel Core i7-3540M central processing unit and with 8 GB of RAM.

\subsubsection{Simulation 2 Results: Disturbance rejection}

The parameter variations and the results for Simulation 2 are shown in Figs. 10-12. The implemented parameter variations are shown in Fig. 10, the controlled variables in Fig. 11 and the manipulated variables in Fig. 12.

Table 6: Error analysis of set-point changes to controlled variables with full state feedback $(F S F)$ and state estimation $(E s t)$.

\begin{tabular}{ccc|ccc|ccc}
\hline & Time [h] & SP & \multicolumn{3}{c|}{$F S F$} & \multicolumn{3}{c}{ Est } \\
& & & $\mu$ & $\sigma$ & NRMSE & $\mu$ & $\sigma$ & NRMSE \\
\hline \hline LOAD & $0-7$ & 0.313 & 0.313 & 0.004 & $1.56 \mathrm{e}-2$ & 0.314 & 0.005 & $1.92 \mathrm{e}-2$ \\
\hline \multirow{3}{*}{ PSE } & $0-1$ & 0.600 & 0.602 & $1.58 \mathrm{e}-4$ & $2.74 \mathrm{e}-4$ & 0.602 & $0.64 \mathrm{e}-2$ & $1.12 \mathrm{e}-2$ \\
& $1.3-3$ & 0.650 & 0.650 & $5.42 \mathrm{e}-4$ & $8.63 \mathrm{e}-4$ & 0.648 & $0.75 \mathrm{e}-2$ & $1.19 \mathrm{e}-2$ \\
& $3.3-5$ & 0.625 & 0.625 & $4.65 \mathrm{e}-4$ & $7.45 \mathrm{e}-4$ & 0.626 & $1.31 \mathrm{e}-2$ & $2.11 \mathrm{e}-2$ \\
& $5.3-7$ & 0.650 & 0.650 & $6.48 \mathrm{e}-4$ & $10.4 \mathrm{e}-4$ & 0.650 & $1.23 \mathrm{e}-2$ & $1.89 \mathrm{e}-2$ \\
\hline \multirow{3}{*}{ THP } & $0-2$ & 20.9 & 20.9 & $4.30 \mathrm{e}-2$ & $2.11 \mathrm{e}-3$ & 20.8 & 0.697 & $3.38 \mathrm{e}-2$ \\
& $2.3-4$ & 22.2 & 22.2 & $2.49 \mathrm{e}-2$ & $1.15 \mathrm{e}-3$ & 22.1 & 0.943 & $4.26 \mathrm{e}-2$ \\
& $4.3-6$ & 23.2 & 23.3 & $5.91 \mathrm{e}-2$ & $3.44 \mathrm{e}-3$ & 22.9 & 0.969 & $4.33 \mathrm{e}-2$ \\
& $6.3-7$ & 22.7 & 22.7 & $0.39 \mathrm{e}-2$ & $1.79 \mathrm{e}-4$ & 22.7 & 0.796 & $3.51 \mathrm{e}-2$ \\
\hline
\end{tabular}



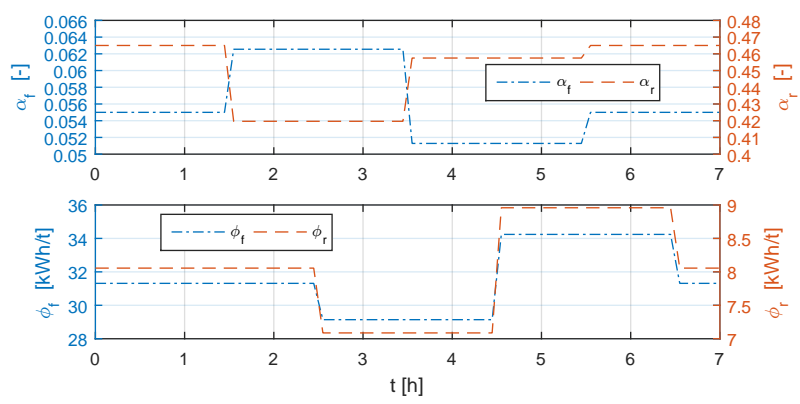

Figure 10: Variation of ore feed size distribution $\left(\alpha_{r}\right.$ and $\left.\alpha_{f}\right)$ and ore hardness $\left(\phi_{r}\right.$ and $\left.\phi_{f}\right)$


Figure 11: NMPC controlled variables for Simulation 2: fraction of mill filled (LOAD), product quality (PSE) and product throughput $(T H P)$.

(Legend: Sim - simulation with full state feedback; Est - simulation with feedback through estimation; Setpoint - variable set-point.)

Fig. 11 shows the response of the system to parameter variations. The decrease in hardness $\left(\phi_{r}\right.$ and $\left.\phi_{f}\right)$ at $t=2.5 \mathrm{~h}$ generally corresponds to an increase in $P S E$ and $T H P$, and a decrease in $L O A D$. The softer rock breaks more readily and therefore reduces the amount of grinding media available. Grinding media refers to rocks and balls responsible for impact breakage. The controller compensates for this by increasing $M F B$ to increase the available grinding media. There is also a gradual decrease in $C F F$ to keep $P S E$ at set-point rather than allowing it to increase. Since the controller is not tuned to control $L O A D$ very tightly, a reasonable degree of variation is allowed to more tightly reject disturbances on PSE and THP. In the

Table 7: Mean and maximum calculation time for NMPC and Particle Filter.

\begin{tabular}{cc|cc}
\hline & & $\mu$ & Max \\
\hline \multirow{2}{*}{ NMPC [min] } & FSF & 0.231 & 0.522 \\
& Est & 0.392 & 0.545 \\
\hline Particle Filter [s] & Est & 0.482 & 0.902 \\
\hline
\end{tabular}



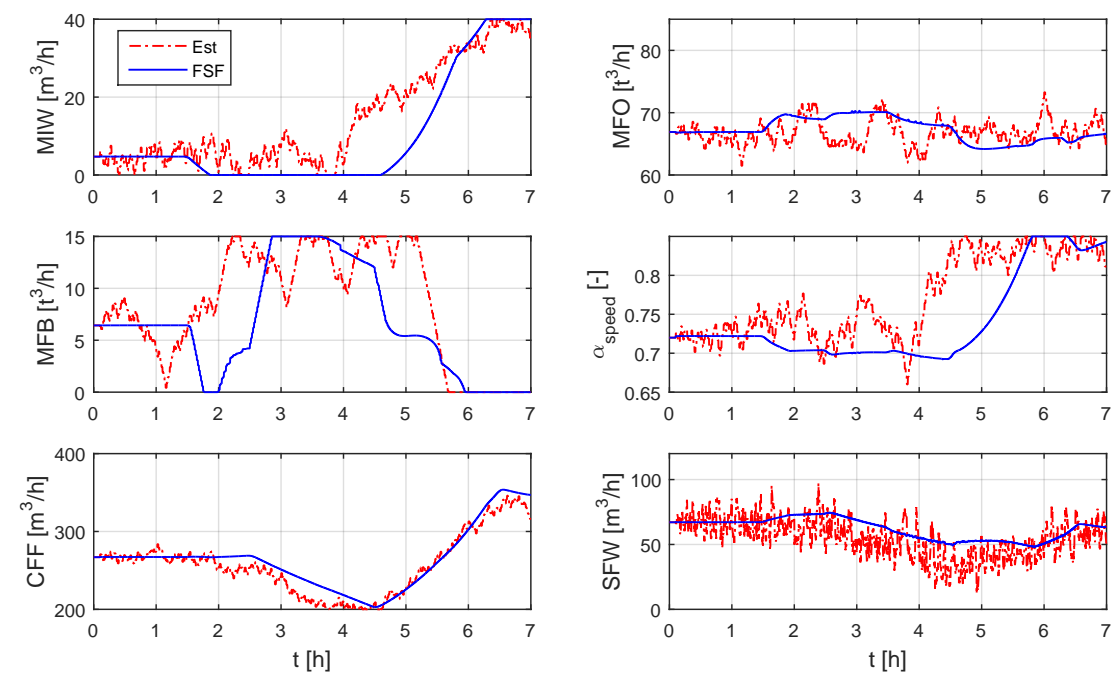

Figure 12: Manipulated variables for Simulation 2: mill inlet water $(M I W)$, mill feed ore $(M F O)$, mill feed balls $(M F B)$, fraction of critical mill speed $\left(\alpha_{\text {speed }}\right)$, cyclone feed flow $(C F F)$, and sump feed water $(S F W)$.

(Legend: FSF - full state feedback; Est - feedback through estimation.)

case of control with full state feedback, $M F O$ in Fig. 12 increases slightly at $t=1.5 \mathrm{~h}$ to compensate for the slight decrease in the fraction of rock $\left(\alpha_{r}\right)$ entering the circuit.

At $t=4.5 \mathrm{~h}$ the ore becomes much harder $\left(\phi_{r}\right.$ and $\phi_{f}$ increase) and more energy is required to break the ore. Since the harder ore means more rocks remain in the mill as grinding media, $M F B$ reduces. To keep $P S E$ at set-point, $C F F$ gradually increases. Since it is required to keep $T H P$ constant, $M F O$ does not change dramatically. Rather, $\alpha_{\text {speed }}$ increases at $t=4.5 \mathrm{~h}$, with a resulting increase in power, as more power is necessary to increase the power necessary to break the harder ore. The variation of $L O A D$ from set-point is not of great concern as the controller was tuned such that $L O A D$ can vary within reason to allow PSE and THP to remain at set-point.

Although the disturbance term $D$ in $(28)$ does provide the ability to reject model-plant mismatch to a certain extent, it does not fully reject the measurement noise propagated through the state estimates. This is most evident in the variation seen in THP. Although a disturbance observer would be preferable to estimate the model-plant mismatch, the disturbances in this case are not observable from the available mill measurements.

\subsection{Discussion}

The NMPC has 6 degrees of freedom to control LOAD, PSE and THP. The coupling between variables complicate the task of assigning optimal regions of operation for all manipulated variables. For example, as shown by Craig et al. (1992a), it is not necessarily the absolute value of $C F F$ that controls PSE, but rather the relationship between $C F D$, as determined by $X_{s w}$, and $C F F$ that controls $P S E$. Furthermore, Craig et al. (1992a) used $M I W$ to extend the range of $P S E$ control in the case where $C F F$ operated close to its constraint. However, in Viklund et al. (2006) $M I W$ is used to maintain the correct mill charge density to ensure consistent THP in the circuit. Viklund et al. (2006) also makes use of $\alpha_{\text {speed }}$ to ensure the correct $P S E$ at a constant THP. This is confirmed in Powell et al. (2009) where it is shown how $\alpha_{\text {speed }}$ has a significant impact on THP and PSE for a specific $L O A D$. Therefore, because of the coupling between variables, it is not necessarily the absolute values of variables that matter, but rather the relationship between the variables. It is the task of the controller to manage the trade-off between manipulated variables to best achieve the goals articulated in its objective function. 


\section{Conclusion}

This paper aims to achieve independent control of PSE and THP using non-linear model-based control. Since the computational expense of NMPC hinders its industrial application, the controller should allow sufficient time to solve the optimisation problem. To achieve these goals, a combination of an NMPC controller and a DI controller is proposed as control architecture. The DI controller, with its low computational cost, is responsible for the fast dynamics of the sump, whereas the NMPC, with its high computational cost, is responsible for the slow dynamics of the circuit.

As shown in Fig. 7, the control architecture is able to achieve independent set-point tracking of PSE and $T P$ as long as the operating conditions of the plant do not exceed the constraints of the manipulated variables. The DI controller operates at $10 \mathrm{~s}$ sampling intervals, whereas the NMPC controller operates at 1 min sampling intervals. Table 7 shows the NMPC controller has sufficient time to solve the optimisation problem, which indicates computational cost should not impede application of the controller.

An estimation architecture is required for state feedback to the controller. To ensure industrial relevance, the state estimator proposed in this paper only makes use of variables which can be practically measured. The sump states are calculated algebraically, whereas the mill states are estimated by means of a particle filter. Fig. 9 indicates the estimation scheme provides adequate estimates of the mill and sump states. However, further research is required to improve estimation of the mill rock and ball volume.

Because the controller is model-based, compensation for model-plant mismatch is required. The feedback term $D$ in (28) allows a sufficient degree of model-plant mismatch rejection as shown in Fig. 11. The ability to reject model-plant mismatch depends on the operating space defined by the bounds of the manipulated variables.

In summary, the novel contribution of this work is the integration of a non-linear controller and state estimator for a milling circuit that can independently regulate the product quality and throughput, and that can reject process disturbances. The combination of the NMPC and DI controllers provides an option to reduce the computational expense impeding industrial application of model-predictive control. Simulation results show that the proposed approach has potential to successfully control an industrial run-of-mine ore milling circuit as only variables that can practically be measured are used.

\section{Acknowledgements}

This work is supported in part by the South African National Research Foundation (Grant Number 90533).

\section{References}

Amestica, R., Gonzalez, G. D., Menacho, J., Barria, J., March 1996. A mechanistic state equation model for semiautogenous mills. Int. J. Mineral Proc. 44-45 (SPEC. ISS.), $349-360$.

Arulampalam, M. S., Maskell, S., Gordon, N., Clapp, T., 2002. A tutorial on particle filters for online nonlinear/non-Gaussian Bayesian tracking. IEEE Trans. Signal Process 50, 174-188.

Bauer, M., Craig, I. K., Jan. 2008. Economic assessment of advanced process control - A survey and framework. J. Process Control 18 (1), 2-18.

Bouche, C., Brandt, C., Broussaud, A., van Drunick, W., 2005. Advanced control of gold ore grinding plants in South Africa. Minerals Eng. 18 (8), 866-876.

Chen, X., Zhai, J., Li, S., Li, Q., 2007. Application of model predictive control in ball mill grinding circuit. Minerals Eng. 20 (11), 1099-1108.

Coetzee, L. C., Craig, I. K., Kerrigan, E. C., Jan. 2010. Robust nonlinear model predictive control of a run-of-mine ore milling circuit. IEEE Trans. Control Systems Tech. 18 (1), 222-229.

Craig, I. K., Hulbert, D. G., Metzner, G., Moult, S. P., 1992a. Extended particle-size control of an industrial run-of-mine milling circuit. Powder Tech. 73 (3), 203-210.

Craig, I. K., Hulbert, D. G., Metzner, G., Moult, S. P., 1992b. Optimized multivariable control of an industrial run-of-mine circuit. J. S. Afr. Inst. Min. Metall. 2, 169-176.

Craig, I. K., MacLeod, I. M., 1995. Specification framework for robust control of a run-of-mine ore milling circuit. Control Eng. Practice 3 (5), 621-630.

Craig, I. K., MacLeod, I. M., 1996. Robust controller design and implementation for a run-of-mine ore milling circuit. Control Eng. Practice 4 (1), 1-12. 
Cuevas, A., Cipriano, A., July 2008. State and ore hardness estimation in semiautogenous grinding. In: 17th IFAC World Congress. Seoul, Korea, pp. 3310-3315, DOI: 10.3182/20080706-5-KR-1001.00562.

Douchet, A., Godsill, S., Andrieu, C., 2000. On sequential monte carlo sampling methods for bayesian filtering. Stat. Comput. 10, 197-208.

Enns, D., Bugajski, D., Hendrick, R., Stein, G., 1994. Dynamic inversion: an evolving methodology for flight control design. Int. J. Control 59 (1), 71-91.

Hinde, A. L., Kalala, J. T., April 2009. The application of a simplified approach to modelling tumbling mills, stirred media mills and HPGR's. Minerals Eng. 22 (7-8), 633-641.

Hodouin, D., 2011. Methods for automatic control, observation, and optimization in mineral processing plants. J. Process Control 21 (2), 211-225.

Hulbert, D. G., Craig, I. K., Coetzee, M. L., Tudor, D., 1990. Multivariable control of a run-of-mine milling circuit. J. S. Afr. Inst. Min. Metall. 90 (7), 173-181.

le Roux, J. D., Craig, I. K., 2013. Reducing the number of size classes in a cumulative rates model used for process control of a grinding mill circuit. Powder Tech. 246, 169-181.

le Roux, J. D., Craig, I. K., Hulbert, D. G., Hinde, A. L., 2013. Analysis and validation of a run-of-mine ore grinding mill circuit model for process control. Minerals Eng. 43-44, 121-134.

le Roux, J. D., Craig, I. K., Padhi, R., 2014. Optimal control of grinding mill circuit using model predictive static programming: A new nonlinear MPC paradigm. J. Process Control 24, 29-40.

Matthews, B., Craig, I. K., 2013. Demand side management of a run-of-mine ore milling circuit. Control Eng. Practice 21 (6), $759-768$.

McIvor, R., Finch, J., 1991. A guide to interfacing of plant grinding and flotation operations. Minerals Eng. 4 (1), 9-23.

Meadows, E. S., Rawlings, J. B., 1997. Nonlinear process control. Prentice-Hall, Inc., Upper Saddle River, NJ, USA, Ch. Model Predictive Control, pp. 233-310.

Munoz, C., Cipriano, A., 1999. An integrated system for supervision and economic optimal control of mineral processing plants. Minerals Eng. 12 (6), 627-643.

Nageswararao, K., Wiseman, D. M., Napier-Munn, T. J., May 2004. Two empirical hydrocyclone models revisited. Minerals Eng. 17 (5), 671-687.

Naidoo, M. A., Padhi, R., Craig, I. K., 2014. A new nonlinear suboptimal control design approach for milling circuits. In: 19th IFAC World Congress. Cape Town, South Africa, pp. 9804-9809, DOI: 10.3182/20140824-6-ZA-1003.02130.

Niemi, A. J., Tian, L., Ylinen, R., 1997. Model predictive control for grinding systems. Control Eng. Practice 5 (2), $271-278$.

Olivier, L. E., Craig, I. K., 2013. Model-plant mismatch detection and model update for a run-of-mine ore milling circuit under model predictive control. J. Process Control 23 (2), 100-107.

Olivier, L. E., Craig, I. K., Chen, Y. Q., 2012a. Fractional order and BICO disturbance observers for a run-of-mine ore milling circuit. J. Process Control 22 (1), 3-10.

Olivier, L. E., Huang, B., Craig, I. K., 2012b. Dual particle filters for state and parameter estimation with application to a run-of-mine ore mill. J. Process Control 22 (4), 710-717.

Pomerleau, A., Hodouin, D., Desbiens, A., Gagnon, E., 2000. A survey of grinding circuit control methods: from decentralized PID controllers to multivariable predictive controllers. Powder Tech. 108 (2-3), 103-115.

Powell, M., van der Westhuizen, A., Mainza, A., 2009. Applying grindcurves to mill operation and optimisation. Minerals Eng. 22 (78), 625-632.

Qin, S. J., Badgwell, T. A., 2003. A survey of industrial model predictive control technology. Control Eng. Practice 11 (7), $733-764$.

Ramasamy, M., Narayanan, S. S., Rao, C. D. P., 2005. Control of ball mill grinding circuit using model predictive control scheme. J. Process Control 15 (3), 273-283.

Ristic, B., Arulampalam, S., Gordon, N., 2004. Beyond the Kalman filter: Particle filters for tracking applications. Artech House, Boston.

Savitzky, A., Golay, M. J. E., 1964. Smoothing and differentiation of data by simplified least squares procedures. Analytical Chemistry 36 (8), 1627-1629, DOI: 10.1021/ac60214a047.

Seborg, D. E., Edgar, T. F., Mellichamp, D. A., 2004. Process dynamics and control, 2nd Edition. NJ: Wiley.

Teo, J., How, J. P., Lavretsky, E., June 2009. On approximate dynamic inversion and proportional-integral control. In: Proc. American Control Conference. St. Louis, MO, USA, pp. 1592-1597, DOI: 10.1109/ACC.2009.5160598.

Van der Merwe, R., April 2004. Sigma-point Kalman filters for probabilistic inference in dynamic state-space models. Ph.D. thesis, Oregon Health \& Science University.

Van der Westhuizen, A., Powell, M. S., 2006. Milling curves as a tool for characterising SAG mill performance. In: Proceedings of SAG 2006, Vancouver, B.C., Canada. pp. 217-232.

Venkatasubramanian, V., Rengaswamy, R., Kavuri, S. N., Yin, K., 2003. A review of process fault detection and diagnosis: Part III: Process history based methods. Computers \& Chemical Engineering 27 (3), 327-346.

Viklund, T., Albertsson, J., Burstedt, J., Isaksson, M., Soderlund, J., 2006. Evolution of AG mill control system at Boliden Mineral AB. In: Proc. SAG 2006 Conference. Dept. Mining Eng., University of British Columbia, Vancouver, B. C., Canada, pp. 311-325.

Wei, D., Craig, I. K., Aug. 2009a. Economic performance assessment of two ROM ore milling circuit controllers. Minerals Eng. $22(9-10), 826-839$.

Wei, D., Craig, I. K., 2009b. Grinding mill circuits - a survey of control and economic concerns. Int. J. Mineral Proc. 90 (14), $56-66$.

Xi, Y.-G., Li, D.-W., Lin, S., 2013. Model predictive control - status and challenges. Acta Automatica Sinica 39 (3), $222-236$. 